\title{
LA MEZQUITA DE CÓRDOBA Y EL MOVIMIENTO ARQUITECTÓNICO NEOÁRABE: DE NORTE Y CENTROAMÉRICA A CHILE
}

José Alberto Moráis Morán María Ximena Urbina Carrasco

Pontificia Universidad Católica de Valparaíso*

Data recepción: 2018/02/07

Data aceptación: 2018/05/01

Contacto autores: jose.morais@pucv.cl; ximena.urbina@ead.cl

ORCID: https://orcid.org/0000-0002-0069-5864

ORCID: https://orcid.org/0000-0002-3203-0269

\section{RESUMEN}

Se estudia la fortuna de la mezquita de Córdoba entre los arquitectos neoárabes de finales del siglo XIX y principios del XX, proponiendo un periplo de formas que, partiendo de la Exposición Colombina de Chicago del año 1893, germinaron con cierto éxito en La Habana, Lima y, finalmente, en Chile. Se remarca la importancia de este fenómeno de reinterpretación historicista, menos investigado, frente a la omnipresencia del alhambrismo. Finalmente, se publican datos inéditos y material gráfico sobre estructuras neoárabes chilenas, hasta ahora nunca o escasamente analizados.

Palabras clave: mezquita, neoárabe, Chicago, La Habana, Chile

\section{ABSTRACT}

This study of the fortunes of the Mosque of Cordoba at the hands of the Neo-Moorish architects of the late 19th and early 20th centuries proposes a journey through forms that originate at the Columbian Exposition in Chicago in 1893 and take root to some extent in Havana, Lima and, ultimately, in Chile. The importance of this phenomenon of historicist reinterpretation, the subject of less research than the omnipresence of alhambrismo, is highlighted. Finally, unpublished data and graphic material on the subject of Chilean Neo-Moorish structures, which never been analysed or only sparingly so, is revealed.

Keywords: mosque, Neo-Moorish, Chicago, Havana, Chile

\section{La Alhambra sempiterna}

En el año 1992 Zeynep Çelik publicó un estudio, hoy considerado clásico dentro de la historiografía, donde analizó la fortuna de las supuestas formas orientales de la arquitectura y su asimilación en los pabellones de las exposiciones universales durante el siglo XIX'. En su texto, la Alhambra de Granada se convertía en el gran referente artístico para las versiones del revival historicista, frente a la mezquita de Córdoba, mencionada esporádicamente y sin profundizar en la repercusión que el edificio medieval pudo haber tenido entre los arquitectos decimonónicos².

Desde la aparición de esta investigación, hasta el año 2018, los estudios sobre la arquitectura reinterpretativa de la tradición edilicia islámica medieval durante el siglo XIX y principios del XX han aumentado considerablemente. Precisamen- 


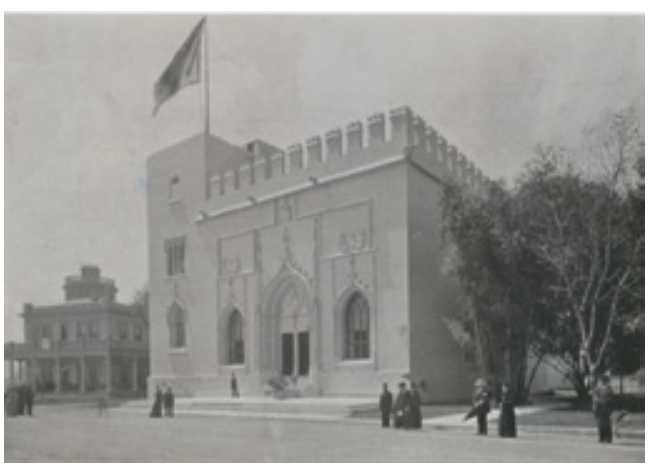

Fig. 1. Rafael Guastavino, Recreación de La Lonja de Valencia, Chicago, 1893. ® Bancroft

te en 2016 vio la luz el trabajo grupal, coordinado por Rafael López Guzmán y Rodrigo Gutiérrez Viñuales, dos de las más reconocidas autoridades en el tema del arte y la arquitectura neoárabe ${ }^{3}$. Tanto en este volumen, como en otros trabajos del último investigador ${ }^{4}$, la Alhambra se muestra como el gran referente artístico para la arquitectura neoárabe de toda América. Esta idea se corroboró a través de sendos actos académicos celebrados en el año 2017. En el "Simposio Internacional América Latina. África del Norte. España. Traslaciones culturales, intelectuales y literarias", se puso el acento en la visión orientalista del arte y la cultura del siglo XIX $X^{5}$. Por su parte, la Universidad de Zurich organizó un congreso enmarcado en el Grupo de Investigación “Mudejarismo and Moorish Revival Project" del Kunsthistorisches Institut, que dirige la Dra. Francine Geise y de cuyo equipo destacamos la publicación, desde el año 2015, de importantes textos dedicados al neoárabe, siempre en una comprensión orientalista del fenómeno'.

El actual encumbramiento de la Alhambra de Granada, bien acreditado científicamente, como referente inspirador para las múltiples versiones de los arquitectos europeos y americanos, es tan sólo la consecuencia de un largo periplo historiográfico que, para el caso español, bien pudo iniciarse teóricamente en la década de los setenta, con las publicaciones de Pedro Navascués?. Se ha considerado al autor como uno de los primeros investigadores en definir el alhambrismo: aplicado a la arquitectura decimonónica, profundizan- do también en este línea durante la década de los 80 los pioneros trabajos de Tonia Raquejo?.

En definitiva, el conjunto de los palacios nazaríes ha terminado por convertirse en un hito omnipresente del llamado neoárabe y la bibliografía de los últimos veinte años así lo defiende. Se analizó su papel en la construcción de un imaginario romántico de tradición orientalista ${ }^{10}$, con estudios más pragmáticos sobre el papel de Rafael Contreras Muñoz (1826-1890) en la restauración del monumento y la exportación de yeserías que se vendían a Europa como una de las principales vía de difusión de sus ornamentos"1.

En este marco cronológico se profundizó también en la relevancia de figuras como Owen Jones y Jules Goury a la hora de divulgar en Europa el patrimonio artístico del edificio granadino ${ }^{12} \mathrm{e}$ incluso se han publicado tentativas de una reflexión terminológica sobre las nomenclaturas estilísticas más pertinentes para definir este movimiento artístico usualmente conocido como neoárabe ${ }^{13}$.

De igual forma, profundos estudios concretaron el rol de la Alhambra en las exposiciones universales ${ }^{14}$, en la construcción de la imagen de España y Andalucía ${ }^{15} \mathrm{o}$ en las repercusiones sobre la arquitectura decimonónica en áreas más orientales $^{16}$. La atención muy detenida que los investigadores han puesto sobre el tema del alhambrismo parece, en el futuro, continuará creciendo, fascinados por las reproducciones realizadas en la Inglaterra finisecular del Patio de los Leones o de las yeserías ${ }^{17}$, así como las impresiones que los palacios granadinos generaron sobre viajeros y estudiosos ${ }^{18}$.

\section{La mezquita soslayada}

La fortuna historiográfica de la mezquita de Córdoba, en el marco de su reinterpretación arquitectónica por los tracistas decimonónicos no corrió tanta suerte y ello a pesar de que la gran aljama llamó desde bien temprano la atención de viajeros y cronistas. Ambrosio de Morales (15131591) y sus influyentes textos, ya remarcaban la relevancia del "famoso y extraño edificio", su horizontalidad, la presencia de almenas y torres, las puertas de bronce, el bosque de "ochocientas y cincuenta columnas (...) que se trajeron de muy lejos de Grecia, o del oriente", loando sus 
mosaicos dorados y, especialmente, la riqueza de materiales y el color, sobre todo en los arcos con "dovelas (...) de piedra y dadas por cima de blanco y colorado". Todo ello ha "puesto admiración a muchos artífices extranjeros" 19 .

El cronista del siglo XVI, al referirse a la obra "morisca", estaba acuñando el término que asumiría la contemporaneidad en los estudios del revival islámico, aportando los datos arquetípicos de las publicaciones del siglo XX: riqueza, columnas, suntuosidad, exotismo y Oriente, como conceptos claves a la hora de examinar el edificio.

Tras Ambrosio de Morales se inició una tradición extensa entre los viajeros que, particularmente en el Romanticismo, se interesaron por el edificio, pero nunca en los términos con los que se abordó la Alhambra granadina ${ }^{20}$.

En este punto resulta necesaria una reivindicación de los autores hispanos. Aunque los dibujos de Owen Jones se han convertido en un supuesto referente pionero en la difusión de los ornamentos alhambristas desde el monumento español a Europa, no ha de olvidarse que estuvieron precedidos por los magistrales diseños de Rafael Contreras. Para el caso de la mezquita de Córdoba, también se han encumbrado como pioneros los de Jean-François Peyron, sin embargo, sabemos que uno de los primeros viajeros en retratar la aljama fue el británico Henry Swinburne 21. El mismo fenómeno se detecta para la extensa y acertada descripción de Ambrosio de Morales, minimizada por los estudiosos europeos ${ }^{22}$.

En este marco cronológico consideramos esencial remarcar el papel que, nuevamente, habrían de tener los eruditos británicos. Twis (1747-1821) se detiene en el año 1775 en el que llama "bosque de columnas", intentando hallar un sistema de lectura simbólica a partir de la cabalística que le permitiese comprender el significado de la obra ${ }^{23}$. Tan sólo cuatro años después Henry Swinburne abordó la construcción ${ }^{24}$. Su texto se acompañó de 7 dibujos de la Alhambra y tan sólo 3 de la mezquita.

Frente a la sempiterna presencia de la Alhambra, ya por entonces epicentro del interés de los escritores y eruditos, la mezquita de Córdoba acabó relegada al margen a finales del siglo XVIII y principios del XIX, documentándose en com-

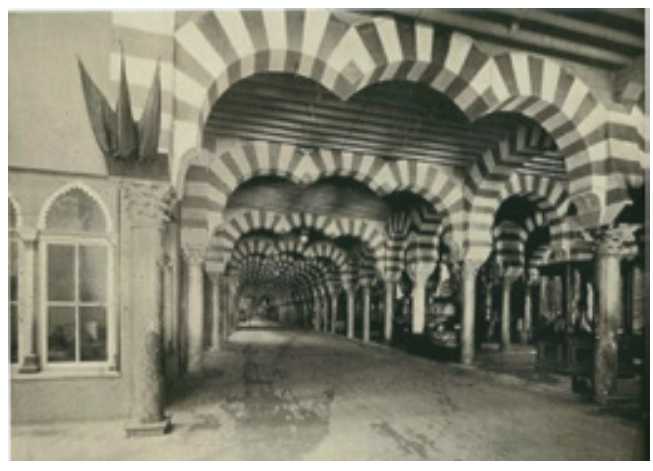

Fig. 2. Joaquín Pavía, Sala de Manufacturas, Chicago, 1893. (B) Ives

paración, menos noticias que reflejen el interés por su conservación y estudio. Sin embargo, ha de remarcarse que, frente a las nefastas prácticas de intervención restauradora en los palacios nazaríes, entre los años 1815 y 1819 se acometieron cuidadas labores en los mosaicos del mihrab de la mezquita por parte del arquitecto italiano Duroni25.

El objetivo de este trabajo no reside en estudiar el acercamiento desde Europa a la mezquita, sino su valorización en América. No obstante, estas imágenes del templo cordobés deben considerarse pioneras en retratar el monumento, tan tempranas como el interés mostrado por Ambrosio de Morales, un precedente por lo general poco valorado y ensombrecido por los testimonios ingleses y franceses ${ }^{26}$.

\section{La mezquita de Córdoba en América del Norte}

Un hito relevante para España y que no ha tenido excesivas repercusiones en los estudios nacionales fue la llamada Exposición Colombina de 1893, realizada en Chicago para conmemorar el IV Centenario de la llegada de Cristóbal Colón a América27. El gobierno español participó activamente e incluso miembros de la familia real acudieron a la muestra, donde se construyó, por ejemplo, una evocación de la Lonja de Valencia, realizada por el arquitecto Rafael Guastavino $(1842-1908)^{28}$ (fig. 1), además de otros edificios que rememoraban el protagonismo de la arquitectura medieval y renacentista hispana. Así fue concebida una sección de San Juan de los Re- 


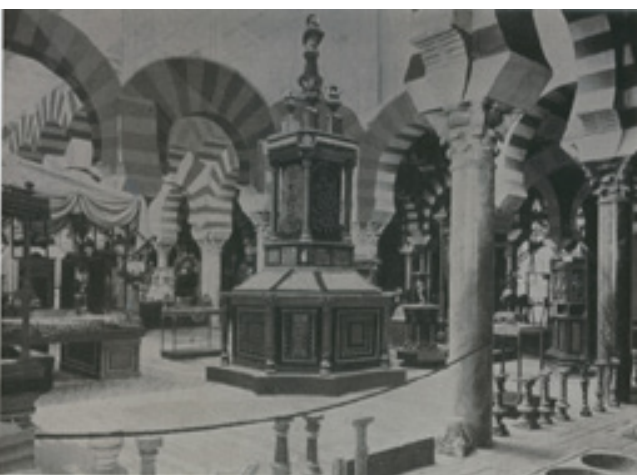

Fig. 3. Joaquín Pavía, Sala de Manufacturas, Chicago, 1893. (B) Bancroft

yes (Toledo), que albergó el llamado Woman's Building o una reproducción del claustro de San Gregorio de Valladolid como sede del Agriculture Building. Otro de los espacios más representativos se organizaba en torno a una evocación del convento de La Rábida (Huelva), trazado a orillas del lago Michigan por William Eleroy Curtis (18501911), jefe de la Oficina de América Latina en los Estados Unidos 29 .

Más importante para nuestro trabajo fue la recreación, en el centro del Midway Plaisance y al lado de la famosa noria, de un edificio neoárabe que se inspiraba directamente en la mezquita de Córdoba, sede del Manufactures and Liberal Arts Building. El comisario catalán Rafael Puig supervisó las obras, trazadas por el arquitecto Joaquín Pavía Bermingham, a la sazón Comisario General de Bellas Artes de la Delegación española en la muestra30 (fig. 2). Como ha señalado Sazatornil, uno de los escasos investigadores españoles que se detuvo en el edificio: " por primera vez en una larga tradición neoárabe se cita exclusiva y expresamente la mezquita de Córdoba" ${ }^{31}$. Con todo, tampoco habrá de olvidarse que en la exhibición de la Johnson Railroad Signal Company, y al otro lado del área ocupada por España, se ubicaron prototipos de "famosas fortalezas y un modelo del puente de Córdoba, cuyos cimientos se construyeron hace casi 2.000 años" 32.

La recreación de la aljama cordobesa coexistió con otros hitos importantes del medievalismo europeo, como en el pabellón de Italia, donde se exhibieron unas reproducciones en miniatura de las puertas de San Marcos de Venecia, insistien-

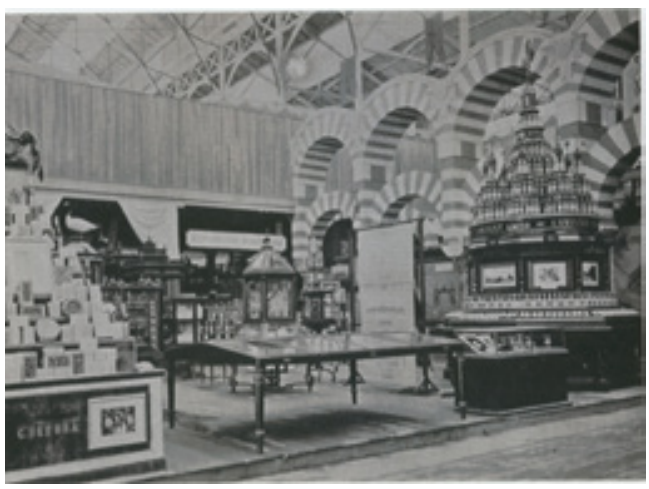

Fig. 4. Joaquín Pavía, Sala de Manufacturas, Chicago, 1893. (B) Bancroft

do las fuentes en los mosaicos y su ascendencia bizantina. Al suroeste de este espacio, como se ha dicho, se ubicó la Sección Española, con sus "melancólicos arcos y sus enormes pilares y sus techos rosas (....) reproduciendo algunas de las características más sobresalientes de la catedral de Córdoba" ${ }^{33}$, con 144 columnas y $163 \operatorname{arcos}^{34}$ (fig. 3).

Las publicaciones derivadas del evento se acompañaron de varias imágenes que sin duda ayudaron en la difusión internacional de la imagen de la mezquita ${ }^{35}$ (fig. 4). En ellas se percibe la recreación de una gran arcada compuesta por doce arcos de herradura, los inferiores, sobre los que apean otros tantos de medio punto, siguiendo el modelo primigenio de tiempos de Abderramán I (780-785) y la primera ampliación de Abderraman II (821-852). En el extremo de esta arcada se recreó también el acceso tríforo de arcos polilobulados de la macsura (fig. 5), levantada por Al-Hakam II en torno al año $966^{36}$. Otro diseño (fig. 6), muy poco conocido, ofrece una vista frontal de este elemento ${ }^{37}$, el más efectista del edificio de Manufacturas y Artes Liberales, que las fuentes consideran excelente, revelando también que los apeos de la recreación se facturaron en mármolis.

Las publicaciones del momento loaron la participación española en la muestra: "Las exhibiciones de España están tan dispersas que no esperaríamos encontrar muchas curiosidades en el edificio del gobierno (se refiere a la reproducción de la Lonja de Valencia, sede de la Comisión es- 


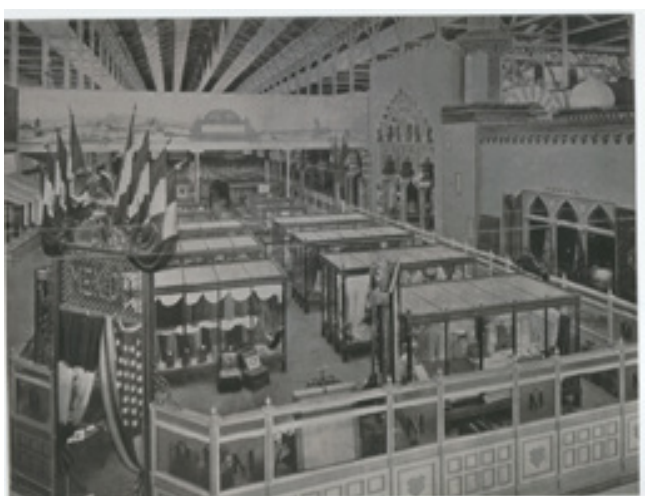

Fig. 5. Joaquín Pavía, Sala de Manufacturas, Chicago, 1893. (B) Bancroft

pañola), pero contiene muchos recuerdos valiosos de Colón; varias de sus cartas están aquí, y una espada presentada por la reina Isabel (...) España ha respondido muy cordialmente a la invitación de los Estados Unidos y sus exposiciones son numerosas e interesantes. Se puede decir que el Convento de La Rábida es un museo español; las tres carabelas son una de sus contribuciones" ${ }^{39}$.

El comisario responsable de la recreación cordobesa, Rafael Puig y Valls, dejó un extenso diario donde relató sus impresiones durante el montaje, que finalizó el 6 de junio de 1893: "Del fac-simil de la mezquita de Córdoba que formó la ornamentación del local (con) (...) arcos y columnas que se cuentan por centenares (...) Tiene este patio forma rectangular, con una puerta central de arcos árabes policromados, al sur; dos puertas de comunicación que dan paso a la Sección italiana, al Oeste; y arcos de las galerías que simulan la mezquita cordobesa, en los lados restantes del rectángulo" ${ }^{40}$.

Parece factible que la elección de la aljama española como monumento referencial de la exposición estuviese vinculada al tenue éxito que el edificio había tenido entre los eruditos europeos pero, sobre todo, se debió a la fama alcanzada por la recreación del Patio de los Leones del Crystal Palace de Londres realizada por Owen Jones (1809-1874) ${ }^{41}$. La omnipresencia de la Alhambra como representante de todo el arte hispanomusulmán en el imaginario colectivo explica la confusión de la prensa estadounidense, que identificó la recreación cordobesa del Midway Plaisance

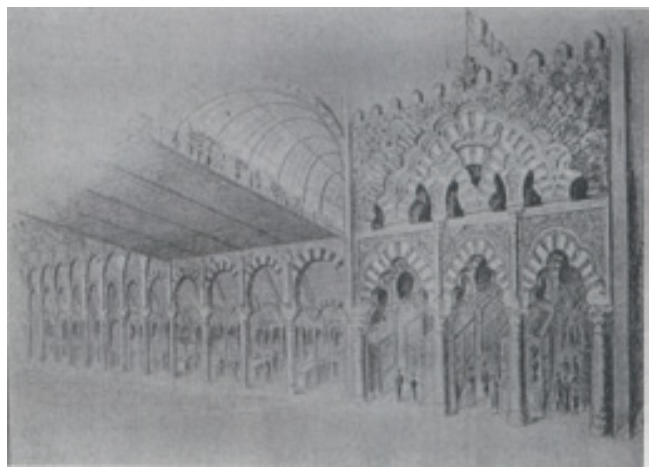

Fig. 6. Joaquín Pavía, Sala de Manufacturas, Chicago, 1893. (B) Bancroft

como una evocación de los palacios nazaríes: "reproducción maravillosa de una magnífica sala en la Alhambra" 42 .

La tendencia alhambrista de hecho continuó en esta muestra al valorar el llamado Palacio Morisco (fig. 7), otra de las atracciones del evento y que evocaba de nuevo y según las fuentes, "el estilo elaborado de la arquitectura morisca", remarcando el uso de esbeltos pilares y capiteles labrados que se multiplicaban gracias un juego de espejos, que "sugieren esa maravilla del arte morisco, la Alhambra"43.

Como puede observarse en este caso, en la percepción finisecular de los eruditos estadounidenses, no existía distinción alguna a la hora de abordar una categorización lógica de la arquitectura islámica conservada en España. Aun tratándose de una de las evocaciones más particulares de la mezquita cordobesa, nuevamente la Alhambra domina el horizonte de acercamiento a este tipo de construcciones. Córdoba y su aljama alcanzaron fama internacional a partir de esta muestra pero, en contra de lo que se ha indicado, la Exposición Colombina de Chicago no evitó en ningún caso el "recuerdo alhambrista"44.

\section{La macsura de La Habana}

Aunque el acercamiento de los arquitectos del eclecticismo y el neomedievalismo a la mezquita cordobesa no alcanzó nunca la dimensión del alhambrismo, existen en Centroamérica indicios que permiten plantear un recorrido de las 


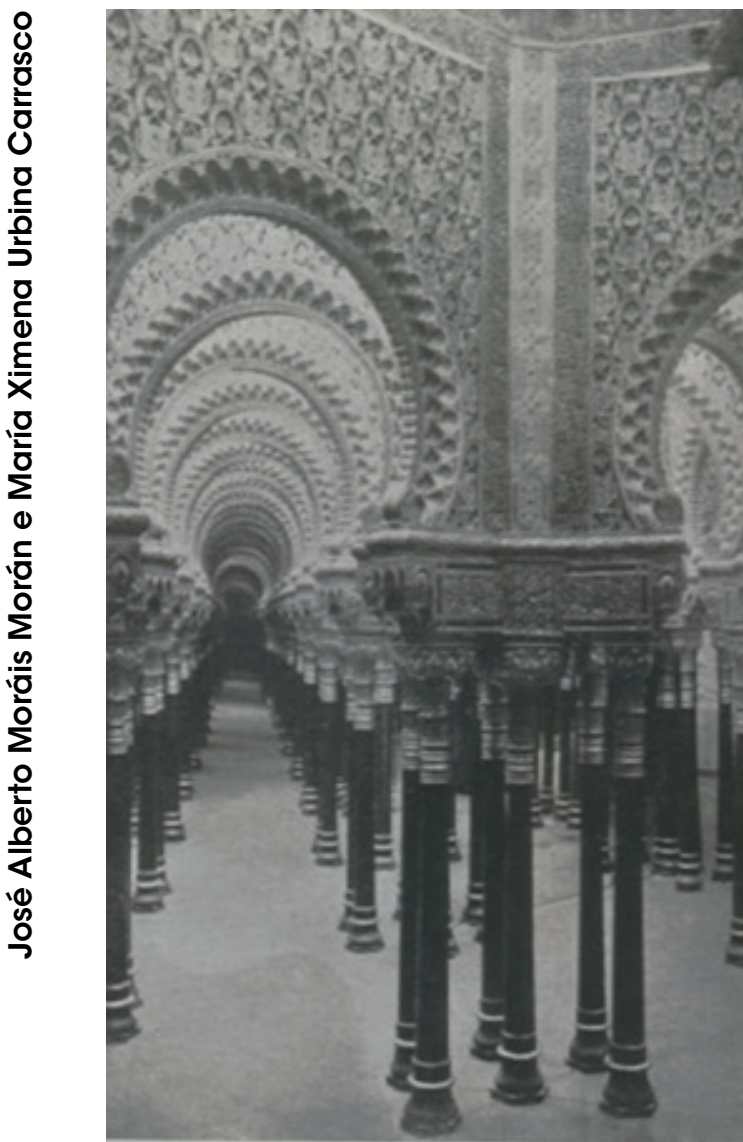

Fig. 7. Gustav Castan, Palacio Morisco, Chicago, 1893. ® Bancroft

formas trasladándose desde el Norte al Sur del continente.

En Cuba se localiza uno de los conjuntos más representativos del neoárabe en Iberoamérica, como ha indicado Rafael López Guzmán ${ }^{45}$. En efecto, la fachada telón del Palacio de las Ursulinas ${ }^{46}$, rememora el que había sido uno de los hitos más llamativos de la Exposición de Chicago: la macsura de la mezquita de Córdoba, utilizada aquí como arcada del pórtico del inmueble (fig. 8).

Fue trazado en el año 1913 por el arquitecto cubano José Toraya ${ }^{47}$. Su carrera aparece marcada por la internacionalidad, pues se había graduado en el extranjero y destacó por sus colaboraciones con arquitectos españoles, como Tomás Muir ${ }^{48}$. Sin duda la huella neo-hispanomusulmana se

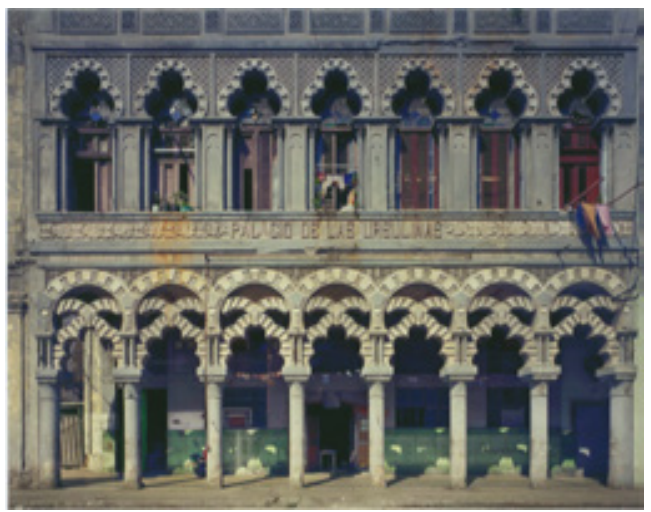

Fig. 8. José Toraya, Palacio de las Ursulinas, La Habana, 1913. (B) Michael Eastman

desarrolló a partir de proyectos auspiciados por la comunidad española residente en Cuba, como demuestra la poco estudiada iglesia de Nuestra Señora de Montserrat, conocida popularmente como ermita de los Catalanes, edificio de historia compleja, que se inició en 1886 y que no se finalizó hasta 1921, para acabar finalmente demolido. Fue patrocinada por la Sociedad de Beneficencia de Naturales de Cataluña, en el camino de Rancho Boyeros y sufrió múltiples reformas, entre ellas las acometidas por el cubano Raúl Otero, en el año 190549, otorgándole un aspecto más defensivo. Ante la destrucción del primer templo la comunidad catalana reedificó otro, concluido en 1954 por los arquitectos catalanes Vicente J. Sallés y Francisco G. Padilla (fig. 9). La prensa coetánea indicó que la construcción se había inspirado en un templo español, conocido a partir de unas fotografías de una Guía de la Costa Brava, del año 1941. Este dato sin duda demuestra las vías utilizadas en América para inspirar la concepción de los edificios ${ }^{50}$.

Con todo, la monumental puerta de acceso al recinto ajardinado, formada por arcos de herradura y rematada con merlones escalonados se aleja lentamente de los modelos cordobeses y andalusíes, ya sometidos a demasiadas referencias eclécticas. No obstante, lo que permite confirmar los ejemplos citados fue el encumbramiento de los arcos de herradura de dovelas bícromas, elemento identificativo por antonomasia de la mezquita cordobesa y que pronto acabaron por estereotiparse dentro de las construcciones finiseculares de todo América del Sur. 


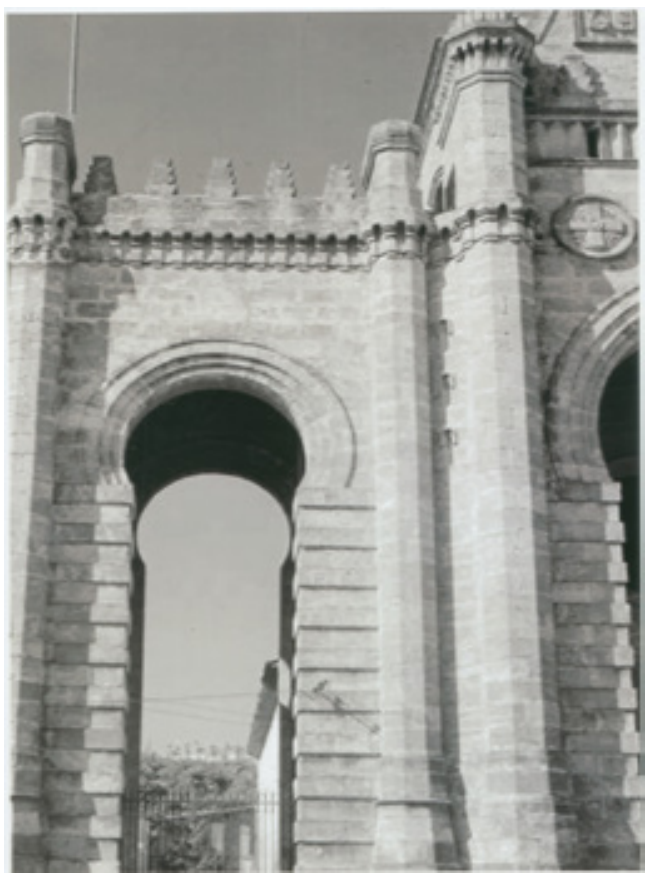

Fig. 9. Nuestra Señora de Montserrat, Rancho Boyeros, La Habana. ${ }^{\circledR}$ Colección Chano Cubano

\section{Lima y los arcos de herradura bícromos}

Paralelamente a las experiencias edilicias analizadas y en un espacio geográfico transitorio hacia la asimilación de esta particular vertiente del neoárabe en Chile, cabe destacar la figura del Alfredo Benavides, quien trazó el hipódromo "de estilo morisco" ${ }^{51}$ de San Beatriz, en Lima, entre 1903-190952 (fig. 10). En la concepción de esta estructura, calificada ya por los estudiosos como neo mudéjar, la presencia de arcos de herradura con dovelas que alternaban el rojo y el blanco se convierte en el eje discursivo de la fachada ${ }^{53}$.

Sin embargo, resulta aún más interesante que este edificio, además, acabase formando eje urbanístico con otra obra neoárabe relevante. En el año 1921 la colectividad española en Perú erigió en el Parque de la Exposición y con motivo del centenario de la independencia del país andino ${ }^{54}$, el llamado Arco Morisco: "Casi a su frente queda el Arco Morisco de los Españoles y a ese mismo sector convergen las Avenidas Leguía, General Arenales y la entrada al Hipódromo de Santa Beatriz" 55, "a la manera de los arcos de la Mez-

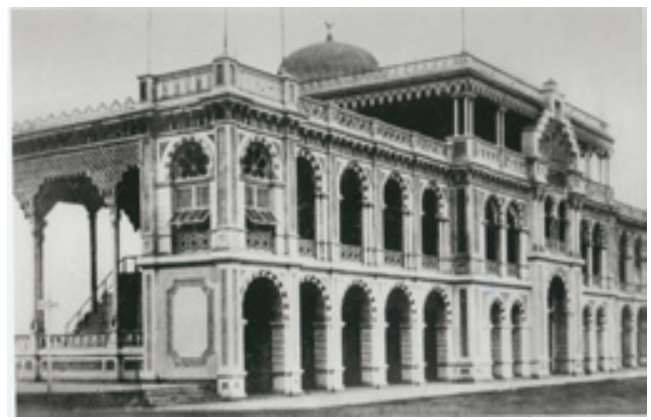

Fig. 10. Alfredo Benavides, Hipódromo de Santa Beatriz, Lima, 1903-1909. ® Pontificia Universidad Católica de Perú

quita de Córdoba"56 (fig. 11). Ciertamente la amplitud del arco peruano muestra resonancias del gran arco de herradura de la capilla de Villaviciosa de la mezquita y, tampoco parece casual que en la recreación neoárabe se utilicen 29 dovelas de colores alternantes, exactamente las mismas que poseen las puertas de San Ildefonso, la de Al Hakan II o la de San Miguel57. Nuevamente la aljama cordobesa aflora en este periplo que, de manera paralela en varios países, colonizaba sutilmente la estética edilicia del cono Sur.

En Lima, estas nuevas concepciones urbanas dominadas por el neoárabe, surgieron simultáneamente al florecimiento de una estética orientalizante, presente tanto en las artes pictóricas como en la literatura ${ }^{58}$, una suerte de énfasis hispanista que redundaba, como lo había hecho toda la Europa del siglo XIX, en los tópicos exóticos de tamiz "arábigo-hispano" 59.

\section{Chile: alhambrismo cordobés e inercia de los modelos}

La presencia de Chile en el exposición estadounidense de 1893 fue muy limitada ${ }^{60}$, destacando las fuentes su especial geografía, su territorio salvaje y rocoso, "frío y triste (pero) más afortunado en el paisaje que Suiza" ${ }^{61}$. Los textos emanados de la muestra insisten en "un país de gran superficie, enorme riqueza natural, maravillosa belleza física y grandes posibilidades. Sin duda, merece una dominación por una raza digna"62.

El siglo XIX norteamericano y, parcialmente, el europeo, encumbró a Chile como heredero de la cultura española. Se consideró a los nativos des- 


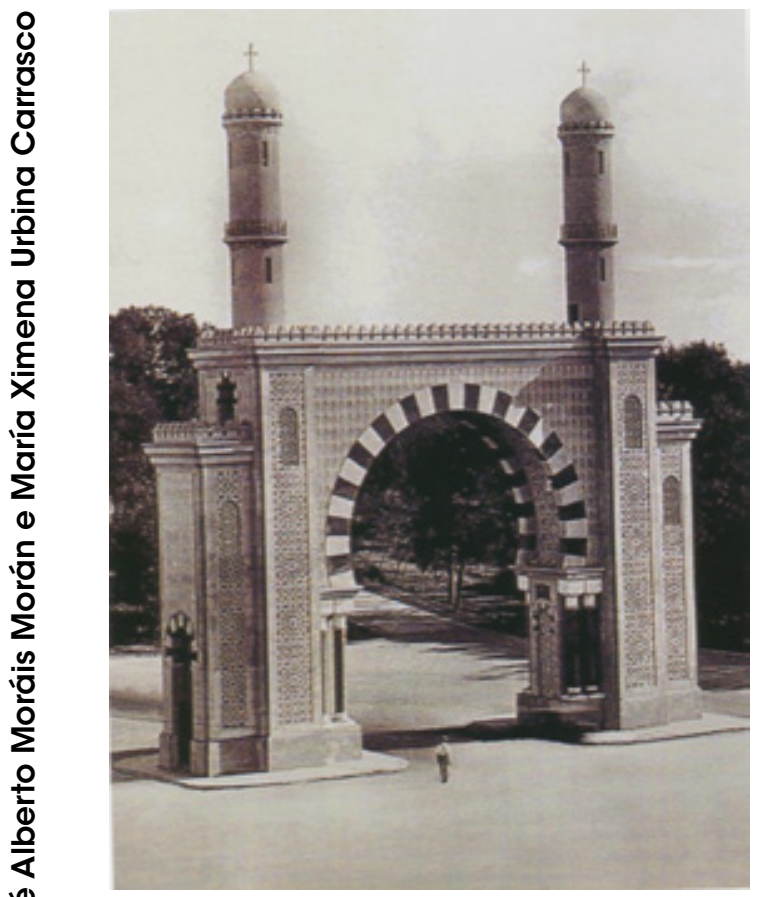

Fig. 11. Arco Morisco, Lima, 1912. ® Arkiv Perú

cendientes de las maneras y gustos ibéricos, "hay mucho de sus antepasados españoles sobre ellos. Han conservado su belleza española"63.

Es difícil documentar hoy el impacto que la exhibición tuvo sobre el país. Las difusas noticias, no obstante, pueden focalizarse en la figura del capitán Víctor María Concas (1845-1916), personaje que alcanzó cierta celebridad, tanto en Chile como en Chicago, por ser el líder de la comitiva marítima que había partido de España guiando la reproducción de las tres carabelas, remolcándolas por el Atlántico hasta el lago Michigan, donde fueron expuestas. Había sido, igualmente, un personaje esencial en la defensa de los intereses españoles en Valparaíso64.

Determinados factores apuntan a un interesante acercamiento de la arquitectura del Chile de finales del siglo XIX y principios del XX al arte hispanomusulmán y la mezquita de Córdoba, aunque naturalmente las referencias a los palacios nazaríes rigieron el discurso investigativo.

Como otros contextos sudamericanos, también Chile mostró a lo largo de esa horquilla

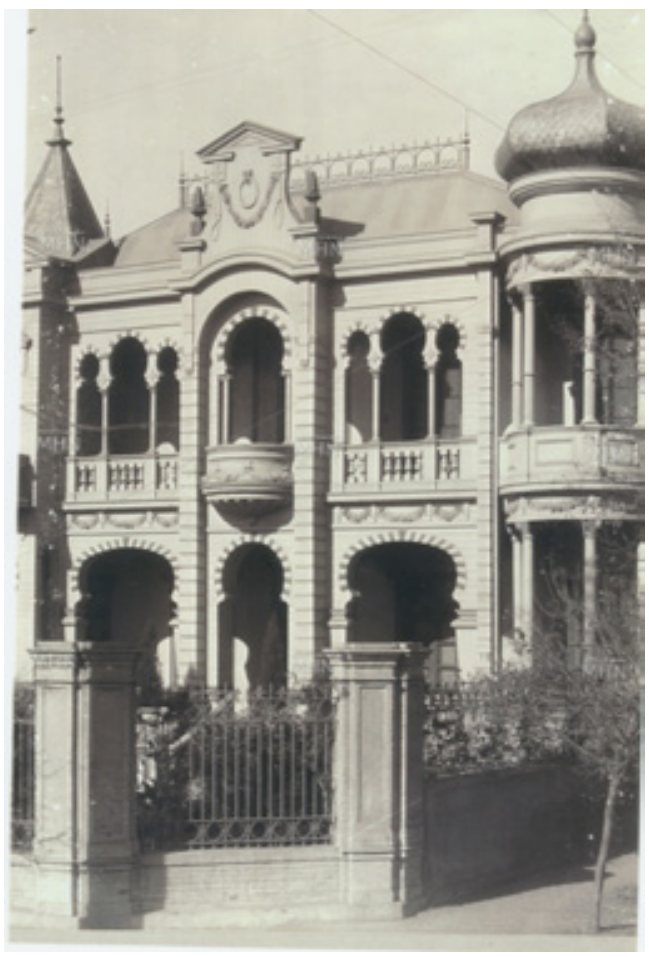

Fig. 12. Esteban Harrington, Palacio Barazarte, Viña del Mar (Chile), 1906-1913. ® Memoria Chilena

cronológica un interés por el llamado arte orientalizante ${ }^{65}$. Como se ha concluido en las investigaciones citadas, al igual que ocurrió en la Inglaterra de Owen Jones o la España de Rafael Contreras, la Alhambra granadina se presenta como hito omnipresente en la construcción de un ficticio imaginario andalusí. Ello lo muestra la fama internacional que alcanzó el llamado palacio de la Alhambra erigido en Santiago por el arquitecto Manuel Aldunate Avaria en el año 1862. Bien conocido en la historiografía, pero carente aún de un estudio monográfico de sus ornamentos y del arquitecto, puede considerarse uno de los primeros ejemplos del alhambrismo en el cono sur. Esta predilección por los palacios nazaríes y su simulación chilena, no obstante, desvió la atención del conocimiento de otros edificios neoárabes levantados en ciudades como Valparaíso, Viña del Mar, lquique o Chillán.

El acercamiento tan precoz a la arquitectura hispanomusulmana desde Chile debe explicarse a partir de la influencia ejercida en el panorama 


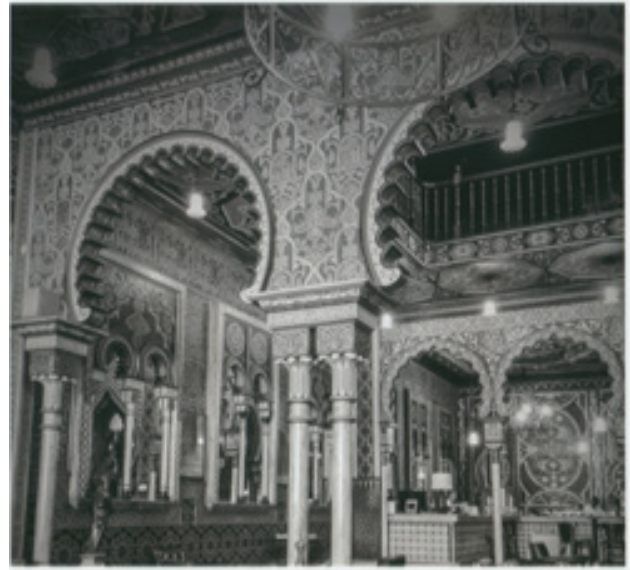

Fig. 13. Miguel Retornano, Casino Español, Iquique (Chile), 1904. ® Casino Español

cultural del país por el arquitecto y teórico Claude François Brunet De Baines (1799-1855). Fue autor del que se ha considerado el primer manual de teoría de la arquitectura de todo América del Sur $y$, a pesar de los continuados deslices propios de un autor decimonónico, sus planteamientos son valiosos. En 1853 expuso ideas que debieron interesar a los alumnos de las Clases de Arquitectura de la Sección Universitaria del Instituto Nacional66, que dirigiría y del que precisamente se haría cargo, años más tarde, el propio Aldunate, artífice del palacio de la Alhambra de Santiago.

En el texto de Baines, los musulmanes se presentan como herederos de la tradición bizantina ${ }^{67}$, perfilando un panorama de los elementos más señeros de la arquitectura islámica y mencionado el uso del arco apuntado de la mezquita de Ahmad ibn Tūlūn de El Cairo, que data en 878. El capítulo dedicado a esta arquitectura, con una visión en extremo simple, debió aportar al panorama intelectual chileno el conocimiento de edificios como la Cúpula de la Roca y los dorados del siglo VII, remarcando la profusión de los ornamentos que cree "fueron tomados de los persas" ${ }^{\prime 6}$ y ensayando de explicar el funcionamiento estructural y ornamental de los mocárabes ${ }^{69}$, por ejemplo. España se encumbra en su obra como espacio neurálgico del arte islámico. Su estudio establece incluso tres fases con las que abordar su comprensión, a partir de la llegada a Córdoba de artesanos bizantinos, la presencia

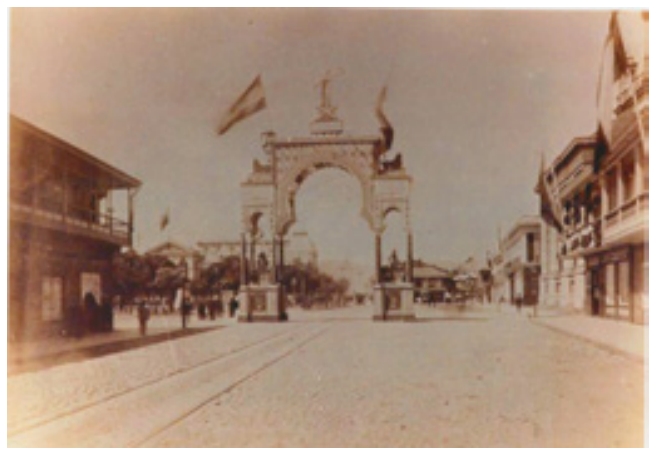

Fig. 14. Fermín Vivaceta, Arco de los Españoles, Valparaíso (Chile), 1881. ® Museo Histórico Nacional, "Arco de los Españoles", sig. AF-54-79

en la mezquita de materiales expoliados de las construcciones romanas, pero errando al considerar que "en cuanto a la influencia de los moros sobre la arquitectura árabe, no sólo es nula sino que todo lo que estos últimos aprendieron del arte de edificar lo deben a los andaluces ${ }^{70}$. Nuevamente la construcción identitaria de una España hegemónica y colonialista se encumbra en el discurso histórico que imagina al pueblo andaluz trasladando conocimientos artísticos a los omeyas. También aquí, la Alhambra capitaliza todo su discurso.

Los estudios que en el futuro se desarrollen deberán intentar soslayar, en la medida de lo posible, la supremacía del alhambrismo en pro de un mejor conocimiento del eclecticismo neoárabe. Gutiérrez Viñuales es uno de los pocos investigadores que se han detenido en este aspecto, discriminando parcialmente los modelos y las soluciones empleadas en el palacio de Aldunate y concluyendo que, incluso en la fachada del palacio santiaguino, no todas las referencias remiten a Granada. Al contrario, el arquitecto conjugó otras soluciones, asumiendo diversas corrientes del neoárabe. Ciertamente no todo emula la Alhambra pues la portada remite a los modelos califales cordobeses, aunque los capiteles en los que apean los cimacios que sustentan el arco del acceso principal son deudores de los diseños que, entre los años 1767 y 1776, realizó José de Hermosilla para las Antigüedades Árabes de España ${ }^{71}$.

Con todo, reaparece de nuevo la mezquita y sus ecos en América, ahora en Chile ${ }^{72}$, amplifi- 
cados por las visitas, cada vez más frecuentes a finales del XIX, de intelectuales, viajeros y literatos que dejaron sus impresiones sobre la aljama cordobesa, como Rafael Sanhueza Lizardi³. En este marco de recepción, si se quiere superficial, de las formas neoárabes descendientes de la recreación decimonónica de la mezquita, sobresale un edificio sobre el que las investigaciones no han deparado, al haber desaparecido.

El palacete encargado por Rafael Daniel Barazarte (1847-1928) al arquitecto porteño Esteban Orlando Harrington (1873-1936), se erigía en la calle Álvarez de Viña del Mar (Valparaíso)74 (fig. 12). Como era habitual entre las clases pudientes de este contexto, la saga, de origen vasco, había hecho fortuna a partir de las explotaciones salitreras ${ }^{75}$.

El conocimiento de la arquitectura desarrollada por entonces en Estados Unidos, además de la exhibida en las exposiciones universales, le llegó al arquitecto a través de su padre, el Vicecónsul estadounidense William Harrington Moss. Debemos a la investigadora Myriam Waisberg el estudio de su trayectoria, muy prolija ante la necesidad de erigir y reconstruir nuevos inmuebles tras el seísmo del año $1906^{76}$.

Harrington concibió importantes edificios públicos en el área porteña, marcados por un sello clasicista de herencia francesa ${ }^{77} y$, particularmente, adaptó los modelos de la arquitectura victoriana realizada en madera en otras áreas de América del Norte y Australia a la peculiar topografía de Valparaíso y Viña del Mar. Son cuantiosas las construcciones que realizó en el área de Playa Ancha ${ }^{78}$, pero, de entre todo el amplio catálogo de viviendas, grandes edificios institucionales y hoteles, la única construcción conocida de este autor donde aparecen soluciones neoárabes es en el palacio Barazarte. La documentación no aporta datos sobre su construcción, pero una primera fotografía del inmueble vio la luz en el año 190679, data ante quem de su trazado.

El frontis del palacete se acompaña con estructuras de tradición clásica francesa, propias del siglo XIX, mostrando un neoárabe demasiado ecléctico que habla de las referencias lejanas que posee el arquitecto y no de una inspiración directa en los modelos cordobeses. No obstante, destaca el dovelaje bícromo, así como el uso de una logia articulada por arcos de herradura, apeada en finas columnas con capitel corintioso.

Las soluciones específicas desarrolladas aquí por Harrington deben enmarcarse en la corriente neoárabe presente en la arquitectura chilena por entonces, aunque fuese en sus múltiples facetas y fuentes de inspiración. Como se ha dicho, el movimiento se inició con el palacio de la Alhambra de Aldunate (1862), continuó, entre otros edificios, con la mansión Díaz-Gana (1872-1875) de Santiago, trazada por el alemán Theodor Burchard o los mausoleos del Cementerio General de la capital (1896), del italiano Teobaldo Brugnolis1.

Sin embargo, la adopción de los arcos de herradura bícromos que encontramos en el palacio Barazarte se manifiesta como un unicum entre los modelos usados en las construcciones coetáneas. A pesar de ello, se trata de una solución estereotipada que posee su origen remoto en la rememoración de la mezquita cordobesa de la Exposición de Chicago. Esta referencia a la muestra no sería la única documentada en Chile.

En el año 1904 el arquitecto español Miguel Retornano finalizó en Iquique la fachada y los salones del Casino Español, "en estilo morisco, que incluye en su interior, además una recargada y cromática decoración" 82 .

Las fotografías de época muestran el salón de billares (fig. 13) articulado mediante una arquería triple de arcos de herradura angrelados o festoneados, que voltean sobre cimacios apeados en estilizados fustes de columnas dobles. Retornano decoró las enjutas con motivos geométricos seriados. Nuevamente el esquema compositivo remite a sus lejanos orígenes alhambristas comprensibles, aunque sea parcialmente, a partir de la difusión que en América había alcanzado el llamado laberinto del Palacio Morisco de Chicago ${ }^{83}$ (fig. 7), cuyo esquema esencial fue precisamente el utilizado por Retornano.

Finalmente, es posible incluso que el arco efímero erigido en la calle Baquedano de Valparaíso por la comunidad de españoles, homenajeando al ejército chileno regresado de la Guerra del Pacífico, se anticipase a todas estas experiencias constructivas (fig. 14).

Esta relevante obra neoárabe ha pasado desapercibida para los estudiosos, aunque se trata 
de uno de los ejemplares más tempranos del contexto chileno. Fue erigido en 1881 y se ubicaba en la plaza de la Victoria. Las fuentes de ese año indican que "representaba la entrada de un salón interior de la Alhambra. Era una linda pintura gótica, adornada con inscripciones. Su lema decía: los españoles de Valparaíso al ejército y marina. Fue construido por don Fermín Vivaceta y profusamente iluminado. Ha sido, sin duda, el de mayor costo (poseía) dos grandes riquísimas banderas de seda, del mejor paño de Lyon, que iban en su coronación: una chilena y otra española" 84. Conocemos su imagen a partir de la fotografía conservada en el Museo Histórico Nacional85.

El alhambrismo resurge de nuevo con la figura de Vivaceta Rupio (1829-1890), alumno de Brunet de Baines, y primer arquitecto autorizado por el gobierno chileno desde el año 1853, aunque extraño al ejercicio de esta tendencia estética ${ }^{86}$. Buen conocedor de las novedades arquitectónicas, aunque nunca viajó a Europa, fue comisario de la Exposición Nacional de Artes e Industrias y poseía una amplia biblioteca de más de 300 volúmenes, " interesantes para arquitectos, ingenieros y constructores. Era una biblioteca escogida, que Vivaceta se había ido procurando desde la edad de 13 años, hasta el día de su enfermedad. Tenía libros en castellano, francés e inglés. Algunas de esas obras no se encontrarían en Chile, ni aún pagándolas a peso de oro" ${ }^{87}$.

A modo de conclusión, podemos indicar que, dentro del movimiento neoárabe de la arqui- tectura de finales del siglo XIX y principios del $X X$, sin duda la vertiente alhambrista ha sido la más investigada. Frente a ello y aunque con una resonancia menor, hemos documentado las repercusiones que la mezquita de Córdoba tuvo en la arquitectura americana, tema menos frecuente en los estudios. El modelo del edificio hispanomusulmán se retomó decididamente en la Exposición de Chicago (1893), mientras que en La Habana se perciben los ecos de la macsura en el palacio de las Ursulinas y, más remotamente, en la ermita de Montserrat (Rancho Boyeros). Las resonancias de los modelos califales se diluyen con formas eclécticas en su tránsito hacia el sur del continente y ello lo prueban las soluciones del hipódromo de Santa Beatriz (1909) y el Arco Morisco de Lima (1912).

Finalmente, Chile adopta fórmulas deudoras de las experiencias chicanenses, sumadas a las nociones teóricas entregadas por Baines. No defendemos una relación directa, sino la prueba de la asimilación de un modelo que, por célebre, fue usado en el palacio Barazarte de forma estereotipada. La necesidad de discernir las fuentes neoárabes, escapando de generalidades, se ha corroborado con el estudio de la composición arquitectónica del Centro Español de lquique. Se concluye también la precocidad de Chile al asumir los repertorios neoárabes, con ejemplos conocidos, como el palacio de la Alhambra de Santiago (1862) o con el arco de la calle Baquedano de Valparaíso, menos estudiado hasta nuestra investigación. 


\section{NOTAS}

* Catedrática y profesor de los Estudios de Posgrado del Instituto de Historia de la Pontificia Universidad Católica de Valparaíso. Este trabajo se enmarca en el Proyecto de Investigación Fondecyt Regular 1170991 "Fundamentos histórico-artísticos del neoárabe y su recepción en Chile (1860-1930)".

1 Z. Çelik, Displaying the Orient: Architecture of Islam at NineteenthCentury World's Fairs, University of California Press, Berkeley, 1992.

2 Se menciona la mezquita cordobesa como referente secundario frente a la Alhambra, para el pabellón español de la exposición de París del año 1878. Señala el autor que, con frecuencia, España utilizaba formas procedentes de los monumentos islámicos "muy probablemente debido a la obsesión por la Alhambra de los ingleses y franceses", desechando la autonomía de los artistas y arquitectos hispanos en la elección de las formas neoárabes. La traducción es nuestra. Cf.: Ibidem, nota 21, p. 69. La otra mención, en las páginas 175-176 de su estudio, se refiere a la utilización del modelo de la gran mezquita hispana por el arquitecto Hénard, a la hora de crear el llamado Palacio de la Electricidad de París, del año 1900.

${ }^{3}$ R. López Guzmán y R. Gutiérrez Viñuales (coords.), Alhambras: Arquitectura neoárabe en Latinoamérica, Almed Ediciones, Granada, 2016. Recogen un corpus de más de 200 edificios que enmarcan en una comprensión orientalista y exótica de la arquitectura, desde Argentina a Estados Unidos. En el trabajo se reúne bibliografía actualizada. Por nuestra parte señalamos que, para el tema que tratamos en esta investigación, son esenciales los documentados trabajos de Rodrigo Gutiérrez. Véase: R. Gutiérrez Viñuales, "El orientalismo en el imaginario artístico y urbano de Iberoamérica. Exotismo, fascinación e identidad", en El orientalismo desde el sur (J. A. González Alcantud, ed.), Anthropos, Sevilla, 2006, pp. 231-259.

${ }^{4}$ R. Gutiérrez Viñuales, "La Alhambra viajera. Rutas americanas de una obsesión romántica", en La Alhambra: lugar de la memoria y el diálogo (J.
A. González Alcantud y A. Abdellouahed, coords.), Comares Editorial, Granada, 2008, pp. 95-122.

5 Organizado por la Dra. Stephanie Fleischmann, ZI Lateinamerika-Institut, FU Berlín, entre los días 6 y 7 de julio de 2017.

${ }^{6}$ Remitimos especialmente a las siguientes: F. Giese y A. Varela Braga (eds.), The Power of Symbols. The Alhambra in a Global Context, Berne, Peter Lang, 2016; F. Giese, A. Varela Braga, H. Lahoz Kopiske, K. Kaufmann, L. Castro Royo, S. Keller, "Resplendence of al-Andalus. Exchange and Transfer Processes in Mudéjar and neo-Moorish Architecture" , Asiatische Studien, 70, 4, 2016, pp. 1307-1353; F. Giese, A. Varela Braga (eds.), Die Appropriation des Orients, SGMOIK Bulletin, 44, 2017.

7 P. Navascués Palacio, Arquitectura y arquitectos madrileños del siglo $X I X$, Instituto de Estudios Madrileños, Madrid, 1973, pp. 263-267.

8 Ibidem, p. 139: "remedo arquitectónico de formas que tienen su origen en la Alhambra de Granada".

9 T. Raquejo, "La Alhambra en el Museo Victoria \& Albert. Un catálogo de las piezas de la Alhambra y de algunas obras neonazaríes", Cuadernos de arte e iconografía, 1, 1988, pp. 201244; ID., El palacio encantado: la Alhambra en el arte británico, Taurus Humanidades, Madrid, 1990 e ídem, "El Alhambresco: Constitución de la imagen romántica de Al-Andalus", en La imagen romántica del legado andalusi, Lunwerg Editores, Barcelona-Madrid, 1995, pp. 29-36. Veáse también: N. Panadero Peropadre, "Recuerdos de la Alhambra: Rafael Contreras y el Gabinete árabe del Palacio Real de Aranjuez", Reales Sitios, 122, 1994, pp. 33-40.

${ }^{10} \mathrm{P}$. Navascués Palacio, "Recorrido artístico por la España romántica", Descubrir el Arte, 30, 2001, pp. 41-49.

$11 \mathrm{~J}$. M. Barrios Rozúa, "José de Contreras. Un pionero de la arquitectura neoárabe. Sus trabajos en la Alhambra", en La invención del estilo hispanomagrebi. Presente y futuro del pasado (J. A. González Alcantud, ed.), Anthropos, Barcelona, 2010, pp. 311-338.

${ }^{12}$ R. Owen, "Coleccionar la Alhambra: Owen Jones y la España Islámica en el South Kensington Museum", en
Owen Jones y la Alhambra (J. Calatrava, ed.), Patronato de la Alhambra y Generalife, Granada, 2011, pp. 42-69; en inglés: pp. 159-168.

${ }^{13}$ Se ha señalado que el término neoárabe resulta arcaico en su aplicación científica, defendiéndose, por ejemplo, su sustitución por el de alhambrismo, neomusulmán o revival islámico, quizás en un ejercicio muy coherente de concretar la naturaleza del movimiento y sus variantes específicas dentro del ingente campo artístico del mediterráneo islamizado: J. M. Rodríguez Domingo, "Neomudéjar versus neomusulmán: definición y concepción del medievalismo islámico en España", Espacio, Tiempo y Forma. Serie VII. Historia del Arte, 12, 1999, pp. 265-285.

14 J. Calatrava, "El arte hispanomusulmán y las exposiciones universales de Owen Jones a Leopoldo Torres Balbás", Awraq, 11, 2015, pp. 7-31 e ídem, "Paradigma islámico e historia de la arquitectura española: de la Exposición Universales al Manifiesto de la Alhambra", en Las exposiciones de arquitectura y la arquitectura de las exposiciones: Las arquitectura española y las exposiciones internacionales (1929-1975) (J. M. Pozo Municio, H. García-Diego Villarías, B. Caballero, coords.), Universidad de Navarra, Pamplona, 2014, pp. 27-36. Véase también: J. M. Rodríguez Domingo, "La Alhambra efímera: el pabellón de España en la Exposición Universal de Bruselas (1910)", Cuadernos de Arte de la Universidad de Granada, 28, 1997, pp. 125-139.

${ }^{15}$ L. Sazatornil, "Andalucismo y Arquitectura en las Exposiciones Universales. 1867-1900", en Andalucía: Una Imagen en Europa (1830-1929), (L. Méndez coord.), Fundación Centro de Estudios Andaluces. Consejería de la Presidencia. Junta de Andalucía, Sevilla, 2008 , s. p. Los trabajos de este autor son esenciales, especialmente para el fenómeno del orientalismo y la importancia del arquitecto alemán Diebitsch: ID., "De Diebitsch a Hénard: el 'estilo Alhambra' y la industrialización del orientalismo", en Orientalismos. Arte y Arquitectura entre Granada y Venecia, (J. Calatrava y Guido Zucconi, eds.), Abada, Madrid, 2012, pp. 53-72. 
${ }^{16} \mathrm{~A}$. McSweeney, "Versions and Visions of the Alhambra in the Nineteenth-Century Ottoman World", West 86th: A Journal of Decorative Arts, Design History, and Material Culture, 22, 1, 2015, pp. 44-69, donde analiza los trabajos de Owen Jones como la vía para difundir el alhambrismo fuera de Europa.

${ }^{17} \mathrm{~J}$. Calatrava, "El arte hispanomusulmán...", pp. 7-31; L. Eggleton; "History in the making: the ornament of the Alhambra and the past-facing present", Journal of Art Historiography, 6, 2012 (consulta: 02/11/2017): https://arthistoriography.wordpress.com/number6-june-2012-2/.

${ }^{18} \mathrm{~A}$. Almagro Gorbea, "Las antigüedades árabes de la Real Academia de Bellas Artes de San Fernando", Antigüedades árabes de España, Real Academia de Bellas Artes de San Fernando, Madrid, 2015, pp. 13-29, donde evidencia -y ello resulta importante- los dibujos de Sánchez Sarabia, "adelantándose en este aspecto a las ideas de estudiosos posteriores como Owen Jones en más de 70 años". Véase también: J. Jiménez Martín, "Notas sobre los dibujos de las Antigüedades árabes", Antigüedades árabes de España, Real Academia de Bellas Artes de San Fernando, Madrid, 2015, pp. 31-43. Sobre la importancia de los dibujos de Owen y las repercusiones de las láminas de la Alhambra aparecidas en Monumentos Arquitectónicos de España en México: R. López Guzmán y A. Y. Avilés García, "Presencia mexicana en la Exposición Universal. El Pabellón morisco de Nueva Orleans (1884)", Awraq, 11, 2015, pp. 59-84.

${ }^{19}$ A. de Morales, Crónica General de España. Antigüedades de las ciudades de España, Benito Cano, Madrid, 1792, vol. 10, pp. 49-66.

${ }^{20}$ Para el caso de los viajeros y las descripciones de Granada realizadas por británicos, véase: J. R. Roelle, That romantic fortress: British depictions of the Alhambra, 1815-1837, Thesis Presented to the Department of Art History, University of Oregon, 2009 (consulta: 15/12/2017). http://citeseerx.ist.psu. edu/viewdoc y P. Navascués Palacio, "Recorrido artístico...", p. 45.

${ }^{21}$ Este autor se adelantó al proyecto de la Real Academia de Bellas Artes de San Fernando, iniciado en el año 1756, pero finalizado íntegramente en 1808. En su obra Travels through Spain (1775-1776) se aportaron datos y dibujos que serían la base para otras obras posteriores, como las realizadas por James Cavanah Murphy o Alexandre Laborde.

${ }^{22}$ Por ejemplo, desde la Universidad de Zurich se indica que el pionero fue Peyron, aunque los primeros dibujos los realizó Swinburne. No se menciona como fuente más antigua y pionera el texto de Ambrosio de Morales (consulta: 22/12/2017: http://wilhelmmeyer. transculturalstudies.ch/en/pioneers/rediscovery.html).

${ }^{23}$ Twis, Travels through Portugal and Spain, in 1772 and 1773, G. Robinson, London, 1775.

${ }^{24} \mathrm{H}$. Swinburne, Travels through Spain in the years 1775 and 1776, Davis, London, 1787.

${ }^{25}$ J. M. Barrios Rozúa, "La Alhambra...", p. 145.

${ }^{26}$ No es un objetivo de esta investigación analizar las obras de John Frederick Lewis y sus litografías de la aljama (1836) o los cuatro grabados que concibió ese mismo año David Roberts. Cf.: A. Gámiz Gordo, "Las vistas de España del viajero David Roberts, pintor de paisajes y arquitecturas hacia 1833", Expresión Gráfica Arquitectónica, n. 15, 2010, pp. 54-65.

${ }^{27} \mathrm{H}$. H. Bancroft, The Book of the Fair, Bancroft, Chicago, 1893; H. Ives, The Dream City: A Portfolio of Photographic Views of the World's Columbian Exposition, Thompson, St. Louis, 18931894; J. Rossiter (ed.), A History of the World's Columbian Exposition, Held in Chicago in 1893, Appleton, New York, 1897, 4 vols.; J. W. Shepp y D. B. Shepp, Shepp's World's Fair Photographed, Globe Bible, Chicago, 1893; T. White y W. Igleheart, The World's Columbian Exposition, Chicago, 1893, Historical Publishing, Philadelphia, 1893.

${ }^{28}$ M. P. Handy, The Official Directory of the World's Columbian Exposition, Chicago, 1893.

${ }^{29}$ El estudio más completo es el de: M. E. Boone, "Marginalizing Spain at the Chicago Columbian Exposition of 1893", Centering the Margins of Nineteenth-Century Art. Nineteenth Century
Studies, 25, 2011, pp. 199-220. El edificio ha recibido mayor atención en la historiografía extrajera: M. Danby y $\mathrm{M}$. Weinreb, The fires of excellence: Spanish and Portuguese oriental architecture, Garnet, Reading, 1997, p. 191.

${ }^{30} \mathrm{El}$ edificio se levantó en un solar irregular, configurando cuatro patios y con poca luz. Se ubicó cerca de las galerías más pequeñas de Argentina, Brasil, México, Persia y Portugal. Estados Unidos, Francia, Alemania y Gran Bretaña ocuparon la mayor parte del espacio, en la parte central. Sobre el arquitecto, véase: E. Casado Alcalde, "Arquitectos de la Academia de España en Roma (siglo XIX)", Archivo Español de Arte, 77, 306, 2004, pp. 129-138.

${ }^{31}$ L. Sazatornil, "Andalucismo...", s. p. Se menciona el edificio neoárabe en: M. J. Bueno Fidel, Arquitectura y nacionalismo. Pabellones españoles en las Exposiciones Universales del siglo XIX, Universidad de Málaga, Málaga, 1987, p. 54; J. Hernando, Arquitectura en España, 1770-1900, Cátedra, Madrid, 1989, p. 246; J. M. Rodríguez Domingo, La arquitectura «neoárabe» en España: el medievalismo islámico en la cultura arquitectónica española (18401930), Tesis Doctoral, Granada, 1997, vol. II, p. 248; P. Navascués Palacio, Arquitectura y arquitectos..., p. 296; D. Canogar, Pabellones españoles en las Exposiciones Universales, Sociedad Estatal Hannover, Madrid, 2000; D. Ortiz Pradas, "En busca de una arquitectura nacional. Mélida y San Juan de los Reyes de Toledo", Anales de Historia del Arte. Volumen Extraordinario, 2010, pp. 257271, particularmente, p. 259.

${ }^{32}$ G. R. Davis, The World's Columbian Exposition, Chicago, 1893, Philadelphia International Pub. Co., Chicago, 1893, p. 278.

${ }^{33}$ Nótese que la define como catedral y no como mezquita: H. H. Bancroft, Op. cit., p. 215, véase el capítulo 9 titulado "Foreign Manufactures"

${ }^{34}$ L. Sazatornil, "Andalucismo...", s. p.

${ }^{35} \mathrm{H}$. H. Bancroft, Op. cit., p. 217, la imagen se publicó bajo el título de "Spanish Section", sin numerar. En la página 218 aparece una vista del área de Argentina y otra con la sección de México, aledañas al pabellón español. 
Otras publicaciones remarcan el carácter orientalizante del pabellón de India. Igualmente se informa sobre la recreación de una mezquita turca, en Midway Plaisance, reproducción de un edificio erigido por el sultán Selim, en Constantinopla, donde se expusieron "gran variedad de objetos interesantes traídos de Oriente". En la misma área se construyó una reproducción de una calle de El Cairo, buscando el éxito alcanzando en París en 1889, cuando se recreó una "Rue du Caire" con gran afluencia de público. El Khedive dio permiso a su arquitecto, Max Hertz, para preparar los diseños y planos, y finalmente, en América, supervisar la construcción. El conjunto estaba configurado por una mezquita que evocaba la del sultán Kaif Bey y un minarete que copiaba el de la "mezquita de Abou Bake Mazhar", todo impregnado de "color oriental". Remitimos también a las descripciones de este texto, con los tópicos islámicos del edificio del teatro argelino y la recreación de una ciudad tunecina. Cf. J. W. Shepp y D. B. Shepp, Op. cit., p. 470 y pp. 500-506 y pp. 514-515.

${ }^{36} \mathrm{~S}$. Calvo Capilla, "La ampliación califal de la mezquita de Córdoba: mensajes, formas y funciones", Goya, 323, 2008, pp. 89-106, en particular, p. 98 y A. Momplet Mínguez, "De la fusión a la difusión en el arte de la Córdoba califal: la ampliación de al-Hakam II en la mezquita aljama", Anales de Historia del Arte. Número Especial II, vol. 22, 237, 2012, pp. 237-258.

${ }^{37}$ G. R. Davis, Op. cit., p. 134.

${ }^{38} \mathrm{~J}$. W. Shepp y D. B. Shepp, Op. cit., p. 478.

${ }^{39}$ Ibidem, p. 478.

${ }^{40}$ R. Puig y Valls, Estados Unidos, Exposición Universal de Chicago, México, Cuba y Puerto, Luis Tasso, México, 1894, pp. 87-88.

${ }^{41}$ J. A. Moráis Morán, "Los islamismos de la arquitectura chilena decimonónica y otras referencias orientales", ARQ Santiago, 95, 2017, pp. 62-73 y M. E. Boone, Op. cit., p. 9. Sobre el debate iniciado en España en torno al factor islámico como representante de la arquitectura y el arte nacional, véase: S. Martin-Márquez, Disorientations: Spanish Colonialism in Africa and the
Performance of Identity, Yale University Press, New Haven, 2008.

${ }^{42}$ The Vanished City: The World's Columbian Exposition in Pen and Picture, The Werner Company, Chicago, 1893.

${ }^{43} \mathrm{~T}$. White y W. Igleheart, Op. cit., p. 590. Por otra parte, no compartimos las relaciones que establece Boone entre el modelo del arco de herradura omeya utilizado para la Sala de Manufacturas con el realizado en este Palacio Morisco: M. E. Bonne, Op. cit., p. 12.

${ }^{44}$ L. Sazatornil, "Andalucismo...", s. p.

${ }^{45}$ Señala el autor que el conocimiento de los modelos del arte andalusí, particularmente la Alhambra de Granada, la mezquita cordobesa y la giralda de Sevilla, se produjo a través de la apertura de la isla a Europa, así como el incremento de viajes y la inmigración española, que dinamizaron la circulación de revistas y los catálogos de las exposiciones universales. Indica que también alcanzaron amplia difusión los diseños de Owen Jones: R. López Guzmán, "Influencias hispanas en la arquitectura de La Habana entre los siglos XIX y XX", Laboratorio de Arte, 27, 2015, pp. 385400.

${ }^{46}$ La historiografía del edificio es limitada. Lo vincula con el romanticismo y el orientalismo ecléctico: J. R. Soraluce Blond, "Arquitectura cubana: vernácula, colonial y ecléctica", en Arquitectura de la casa cubana, Universidade da Coruña, A Coruña, 2001, p. 17. Sobre la historia del complejo religioso de las hermanas madres Ursulinas, procedentes de Nueva Orleans y asentadas en ese lugar desde el año 1803, véase: E. Roig de Leuchsenring, La Habana. Apuntes Históricos, 28, Consejo Nacional de Cultura, La Habana, 1963, vol. II, p. 94 y p. 134 y S. Vázquez Cienfuegos, "Omnia vanitas: festejos en honor de Godoy en La Habana en 1807", Ibero-americana pragensia supplementum, 25, 2009, pp. 115-138. Liga el palacio de las Ursulinas con las sociedades de emigrantes: Y. Farrés Delgado, "Colonialidad territorial y evolución urbana en La Habana", Apuntes, 28-1, 2015, pp. 8-23.

${ }^{47}$ Artífice también, en la misma ciudad y con formas neoárabes, del
Hotel Sevilla: R. Gutiérrez Viñuales, "El orientalismo...", pp. 231-259.

${ }^{48}$ Con el que construye en el año 1909 el edificio de La Lonja del Comercio, ubicado en la plaza San Francisco: E. Roig de Leuchsenring, Op. cit., p. 134.

${ }^{49}$ Ibidem, p. 52.

50 J. Plá, Costa Brava. Guía General y Verídica, Destino, Barcelona, 1941. Véase también: S. A. "La ermita de los catalanes de La Habana", s. p., s. I., donde se indica: "es esta ermita, escueta reproducción de la de San Agaró y la idea de construirla fue por la lectura de la Guía de la Costa Brava de Plá y la consiguiente fotografía que en el libro se publica". Efectivamente la publicación alberga dos instantáneas de la capilla de Nuestra Señora de la Esperanza de S'Agaró Vell. Cf.: J. Ferrán Oliva, La saga de los catalanes en Cuba, Ediciones Casa Amèrica Catalunya, Barcelona, 2009, pp. 139-140.

${ }^{51}$ D. Sainte Marie, Perú en cifras, 1944-1945, Empresa Gráfica Scheuch, Lima, 1945, p. 986.

${ }^{52} \mathrm{~A}$. Vázquez y J. Young, Historia del turf nacional, 1864-1945, Miranda, Lima, 1952, pp. 92-100; R. Gutiérrez Viñuales, "La seducción de la Alhambra. Recreaciones islámicas en América", en Mudéjar Hispano y Americano. Itinerarios culturales mexicanos, (R. López Guzmán, coord.), El Legado Andalusí, Granada, 2006, pp. 166-173.

${ }^{53}$ No obstante, la construcción ya está dominada por un total eclecticismo y se aparta de una visión más o menos empírica de la arquitectura islámica de Córdoba.

${ }^{54}$ E. Martuccelli Casanova, "Lima, capital de la Patria Nueva: el doble Centenario de la Independencia en el Perú", Apuntes, 19, 2, 2006, pp. 256-273. Se levantó en la Avenida Leguía, hoy Arequipa, entre las Embajadas de Argentina y España. Cf.: L. Rodríguez Cobos, Arquitectura limeña: paisajes de una utopía, Colegio de Arquitectos del Perú, Lima, 1983, p. 42, indica: "morisco hispánico como muchas de las residencias que existen a lo largo de la Avenida Arequipa y otras zonas de Lima".

${ }^{55}$ S. A. "Construcción del Lima Country Club. El Mejor Club Campestre 
de Sud América", Ciudad y campo y caminos, núms. 6-15, 1925, pp. 2-8.

${ }^{56}$ R. Gutiérrez Viñuales, "La seducción...", pp. 166-173 e ID., "Arquitectura morisca en Sudamérica", en Alhambras. Arquitectura neoárabe en Latinoamérica ( $R$. López Guzmán y R. Gutiérrez Viñuales, coords.), Editorial Almed, Granada, 2016, pp. 195-213, p. 198. Puesto que la vía de estudio aquí se limita al contexto Perú-Chile y la franja del Pacífico, remito a los trabajos de este autor para localizar otros ejemplos de la expansión del arco bícromo cordobés en la arquitectura de Brasil y Uruguay. El arco peruano fue derruido en 1937 y recientemente reconstruido.

${ }^{57}$ Véase el estudio actualizado de las puertas de: S. Calvo Capilla, "Justicia, misericordia y cristianismo: relectura de las inscripciones coránicas de la mezquita de Córdoba en el siglo X", AlQantara, 31, 1, enero-junio 2010, pp. 149-187.

${ }^{58}$ E. Valero, Lima en la tradición literaria del Perú. De la leyenda urbana a la disolución del mito, Ensayos/Scriptura 12, Ediciones de la Universidad de Lleida, Lleida, 2003, p. 166. Sobre la pintura limeña de inicios de siglo XX y la inserción de la imagen de la mezquita de Córdoba con esta línea orientalista: F. Villegas Torres, Vínculos artísticos entre España y Perú (1892-1929): elementos para la construcción del imaginario nacional peruano, Tesis Doctoral, Universidad Complutense de Madrid, Madrid, 2013, pp. 53-54 у p. 598.

${ }^{59} \mathrm{H}$. Ramos Cerna, Destrucción y reinvención de la Plaza de Armas. Estilo neocolonial y modernización urbana en Lima, 1924-1954, Tesis para optar por el grado de Magíster en Historia del Arte, Pontificia Universidad Católica de Perú, Lima, 2014, p. 35.

${ }^{60}$ Se menciona el país en el apartado de vinicultura, con los productos de Francia, Italia, Portugal y España. Cf.: J. J. Flinn, Official guide to the World's Columbian exposition, Press Chicago, Chicago, 1893, vol. III, p. 82.

$$
{ }^{61} \text { Ibidem, p. } 338 .
$$

62 Ibidem, p. 346.

${ }^{63}$ Ibidem, pp. 347-352. Véase también: J. D. Murillo Sandoval, “De lo natural y lo nacional. Representaciones de la naturaleza explotable en la Expo- sición Internacional de Chile de 1875", Historia (Santiago), n. 1, vol. 48, junio 2015 (consulta: 12/12/2016). S. Dümmer Scheel, Sin tropicalismos ni exageraciones. La construcción de la imagen de Chile para la Exposición Iberoamericana de Sevilla en 1929, RIL Editores, Santiago, 2012, pp. 170-171. Sobre la imagen de Chile en las exposiciones, el papel del vino y los proyectos ferroviarios, consúltese: C. Galeno-lbaceta, "Chile y sus hospitales en pabellones en la Exposición Universal de París de 1889", Sistema arquitectónico de pabellones en hospitales de América Latina (M. L. González Servín, coord.), Universidad Nacional Autónoma de México, Coyoacán, 2011 pp. 87-94.

${ }^{64}$ E. Boone, Op. cit., p. 17.

${ }^{65} \mathrm{M}$. Baros Townsend, El imaginario oriental en Chile en el siglo XIX: orientalismo en la pintura y arquitectura chilena, Editorial Académica Española, Madrid, 2011.

${ }^{66} \mathrm{M}$. Milos Montes, La construcción de la identidad chilena a partir de la Exposición Universal de París de 1889, Tesis presentada a la Facultad de Artes de la Universidad de Chile para optar al grado de Magister en Teoría e Historia del Arte, Santiago, 2014, p. 43, donde analiza la figura del arquitecto en el marco de un afrancesamiento de la estética edilicia. Véase también: M. P. Valenzuela, "La enseñanza de la arquitectura en Chile", de arquitectura, ns. 28-29, 2014, pp. 54-55 y P. Berríos, E. Cancino, C. Guerrero, I. Parra, K. Santibáñez y N. Vargas, "Las bellas artes en la Atenas de Sudamérica: cultura y esfera pública en la República Conservadora", en Del taller a las aulas. La institución moderna del arte en Chile (1797-1910), Estudios de Arte, Santiago, 2009, pp. 127-182.

${ }^{67} \mathrm{C}$. Brunet de Baines, Curso de arquitectura: escrito en francés para el Instituto Nacional de Chile, Imprenta Julio Belin \& Cia., Santiago, 1853, p. 22.

${ }^{68}$ Ibidem, p. 104.

69 Ibidem, pp. 106.

${ }^{70}$ Ibidem, p. 107.

${ }^{71}$ Nos referimos al capitel E de la lámina publicada por Almagro, que soporta el arco central del pórtico sur del Patio de Comares, delante de la Sala de la Barca. Véase: A. Almagro Gorbea,
"Antigüedades Árabes de España. Catálogo", en El legado de al-Ándalus: las antigüedades árabes en los dibujos de la Academia. Catálogo de la exposición, Real Academia de Bellas Artes de San Fernando, Madrid, en particular, ficha catalográfica 57, 2015, pp. 250-251. No hay espacio aquí para analizar este edificio, pero remarcamos que posiblemente Aldunate pudo acceder a este tipo de dibujos para componer los ornatos del palacio chileno.

${ }^{72}$ R. Gutiérrez Viñuales, "Horizontes historicistas en Iberoamérica. El Neoprehispánico y el Neoárabe, exotismo e identidad", en Arquitectura escrita. Doscientos años de arquitectura mexicana, (J. Lozoya y T. Pérez, coords.), Instituto Nacional de Antropología e Historia, México, 2009, pp. 87-99. El autor realiza un ejercicio que deberá servir de ejemplo en el futuro para comprender la complejidad del neoárabe en Chile, pues aunque la Alhambra es el referente para los vanos laterales de la portada, de estilo nazarí, también se introducen elementos de la estética turco-otomana, con el uso del arco mixtilíneo propio de la tradición selyulkíe, entre otras referencias. Desconocemos si ha sido publicada la conferencia de: A. Emparán (Universidad Adolfo Ibáñez, Chile), "Palacio de La Alhambra; un orientalismo chileno del siglo XIX", pronunciada en el Seminario "The Power of a Symbol", en Zurich, 15-17 septiembre de 2016.

${ }^{73}$ R. Sanhueza Lizardi, Viaje en España, Garnier, París, 1889, p. 111 y J. López Quintáns, "Disertaciones y descubrimientos en Viaje en España de Rafael Sanhueza Lizardi", Philologia Hispalensis, 26, 3-4, 2012, pp. 83-95.

${ }^{74} \mathrm{~N}$. Alarcón y M. Brito, "Patrimonio Arquitectónico de Viña del Mar Antiguo: 1880-1930", Seminario de Investigación para optar al título de Profesor de Historia y Geografía, Universidad Católica de Valparaíso, Facultad de Filosofía y Educación, Instituto de Historia, Viña del Mar, 1989, pp. 33-37 у р. 163. Remito al trabajo inédito realizado por A. D. Lillo Brevis, "Influencias orientalistas en la fachada del Palacio Barazarte de Viña del Mar: Una mirada al eclecticismo arquitectónico chileno de finales del siglo XIX e inicios del siglo XX", Trabajo del Magister en Historia. 
Seminario de Especialización II, Pontificia Universidad Católica de Valparaíso, 2017, p. 11. Ante la escasa bibliografía dedicada a esta obra, agradecemos al autor que nos haya permitido consultar su trabajo.

${ }^{75}$ R. Hernández Cornejo, El salitre (resumen histórico desde su descubrimiento y explotación), Fisher Hermanos, Valparaíso, 1930, p. 86.

${ }^{76} \mathrm{M}$. Waisberg, Casas de Playa Ancha: La vivienda a fines del siglo XIX en Valparaíso, Fondo Nacional de DesarroIlo Científico y Tecnológico, Valparaíso, 1988, p. 96. Consúltese también, sobre los aspectos técnicos de sus edificios: M. Hurtado, M. Salazar y G. Muñoz, "Construction features of the historical architecture in the sea port city of Valparaíso: architect E. O. F. Harrington's brick masonry buildings", Revista de la Construcción, n. 3, vol. 15, 2016, pp.67-76.

${ }^{77}$ No existe espacio aquí para abordar esta línea estética del arquitecto. Remitimos al libro titulado: S. A., E. O. F. Harrington. Arquitecto. Valparaíso, Álbum de edificios, s. I., 1910.

${ }^{78} \mathrm{M}$. Waisberg, Op. cit., p. 22.

${ }^{79}$ S. A., Álbum de Viña del Mar, Imprenta Universo, Valparaíso, 1913, s. p.

${ }^{80}$ No hemos podido concretar el material constructivo, posiblemente formado por una cimentación de hormigón, estructuras de madera y adobillo, propio de la arquitectura del momento en este contexto. Las fotografías no permiten asegurarlo pero es factible que se recurriera a una cubrición de madera en la fachada, igual que la utilizada por Harrington en las casonas de Playa Ancha.

${ }^{81}$ T. Domínguez, "Mausoleos exóticos. Eclecticismo y reinvención estilística de Teobaldo Brugnoli", $A R Q$, n. 48, julio 2001, pp. 50-53 y E. Balmaceda Valdés, Un mundo que se fue, Andrés Bello, Santiago, 1969, p. 225.
${ }^{82}$ R. Gutiérrez Viñuales, "Horizontes...", p. 91. Véase sobre todo: S. A., Álbum fotográfico de lquique, Imprenta y litografía de la llustración, Santiago, 1918, lámina 56. Se ha catalogado la obra dentro del "estilo árabe" en: L. F. del Río Barrio y J. F. Sobrevilla Carlino, "Asociaciones de españoles en Chile (1850-1950)", El asociacionismo en la emigración española a América, (J. A. Blanco Rodríguez ed.), Junta de Castilla y León, Salamanca, 2008, pp. 503-523, en concreto p. 511. También se remarcó la "decoración mudéjar" del inmueble, "como un palacete sevillano en medio de la Pampa": M. Peña Muñoz, Memorial de la tierra larga: crónicas chilenas, Ril Editores, Santiago, 2001, pp. 31-46.

${ }^{83} \mathrm{Se}$ ha atribuido el montaje de esta suerte de panóptico con caleidoscopio y un jardín de palmeras a Gustav Castan, relacionándolo "con los pilares y ornamentos de Constantinopla". La estructura fue trasladada desde Chicago un año después a la California Midwinter International Exposition, del año 1894. El neoárabe fue el estilo predilecto de estos montajes, de los que también se han analizado el llamado "Laberinto de Oriente" de la Exposición Nacional de Suiza, en Ginebra, de 1896 y que fue construido en "estilo morisco según el modelo del palacio de la Alhambra de Granada". Cf.: J. Saward, "The Origin of Mirror \& Wooden Panel Mazes", Caerdroia, 37, 2008, pp. 4-12.

${ }^{84} \mathrm{P}$. Ahumada Moreno, "Los arcos y adornos de la ciudad", Guerra del Pacífico. Recopilación completa de todos los documentos oficiales, correspondencias y demás publicaciones, referentes a la Guerra, Imprenta Americana, Valparaíso, 1888, vol. V, pp. 310-313, en particular, p. 312. Sólo lo menciona, sin aportar más datos, aunque publica una fotografía: M. Baros Townsend, Op. cit., p. 73, figura 45.

${ }^{85}$ Santiago, Museo Histórico Nacional, "Arco de los Españoles", sig.
AF-54-79 (ca.) 1881. Fue realizada por Spencer \& Cia. La institución conserva otra similar: "Valparaíso", AF-143-166 (ca. 1905).

${ }^{86} \mathrm{~A}$. Blanco, Vida y obras del arquitecto don Fermín Vivaceta precursor de la sociabilidad obrera en Chile, Talleres Gráficos, Santiago, 1924. Vivaceta prefirió siempre las formas clásicas, en su vertiente neogriega o neoromana, cuando no el ejercicio de reinterpretaciones neoclásicas, siguiendo los modelos franceses. Trata muy escuetamente al arquitecto: M. Pallarés Torres, La arquitectura religiosa en Santiago de Chile 1850-1950. Razones de las reminiscencias góticas, Tesis Doctoral de la Universidad Politécnica de Madrid, Madrid, 2015, pp. 124-125.

${ }^{87}$ A. Blanco, Op. cit., p. 30. Es interesante el análisis de los libros que poseía para conocer los modelos usados en la composición de los edificios. Tuvo una edición de Sette libri dell'architettura de Sebastián Serlio del año 1563, que adquirió en 1852, así como otra edición de 1787 de los Diez libros de Arquitectura de Vitrubio. De 1797 fueron sus ediciones de I quattro libri dell'architettura de Palladio y de I dieci libri de l'architettura de Alberti. Sabemos que poseía también ejemplares de Architecture moderne ou L'art de bien bâtir, de C. Jombert (ca. 1764) y del Album pratique de l'art industriel de C. A. Oppermann. Hemos revisado estas publicaciones y en ninguna de ellas existen referentes a la arquitectura islámica medieval o su reinterpretación neo. Sobre el clasicismo de la obra de Vivaceta y su supuesta reticencia a los lenguajes neomedievales: F. Riquelme, "Fermín Vivaceta. El arquitecto y su obra", Revista de Arquitectura, n. 1, 2-7, diciembre, 1990, pp. 2-7. 


\section{REFERENCIAS}

Ahumada Moreno, Pascual. 1888. "Los arcos y adornos de la ciudad." In Guerra del Pacífico. Recopilación completa de todos los documentos oficiales, correspondencias y demás publicaciones, referentes a la Guerra, vol. V, 310-313. Valparaíso: Imprenta Americana.

Alarcón, Norberto, and Marcel Brito. 1989. “Patrimonio Arquitectónico de Viña del Mar Antiguo: 1880-1930." Seminario de Investigación para optar al título de Profesor de Historia y Geografía. Viña del Mar: Universidad Católica de Valparaíso, Facultad de Filosofía y Educación, Instituto de Historia, Viña del Mar.

Almagro Gorbea, Antonio. 2015. "Antigüedades Árabes de España. Catálogo." In El legado de al-Ándalus: las Antigüedades árabes en los dibujos de la Academia. Catálogo de la exposición, edited by Antonio Almagro Gorbea, ficha catalográfica 57, 250-251. Madrid: Real Academia de Bellas Artes de San Fernando.

Almagro Gorbea, Antonio. 2015. "Las antigüedades árabes de la Real Academia de Bellas Artes de San Fernando." In Antigüedades árabes de España, edited by Antonio Almagro Gorbea, 13-29. Madrid: Real Academia de Bellas Artes de San Fernando.

Anonymous. 1893. The Vanished City: The World's Columbian Exposition in Pen and Picture. Chicago: The Werner Company.

Anonymous. 1910. E. O. F. Harrington. Arquitecto. Valparaíso, Álbum de edificios. s. I.

Anonymous. 1913. Álbum de Viña del Mar. Valparaíso: Imprenta Universo, Valparaíso.

Anonymous. 1918. Álbum fotográfico de lquique. Santiago: Imprenta y litografía de la llustración.

Anonymous. 1925. "Construcción del Lima Country Club. El Mejor Club Campestre de Sud América." Ciudad y campo y caminos 6 (15): 2-8.

Anonymous. S. d. La ermita de los catalanes de La Habana. s. I.

Balmaceda Valdés, Eduardo. 1969. Un mundo que se fue. Santiago: Universidad Andrés Bello.
Bancroft, Hubert Howe. 1893. The Book of the Fair. Chicago: Bancroft.

Baros Townsend, Mauricio. 2011. El imaginario oriental en Chile en el siglo XIX: orientalismo en la pintura y arquitectura chilena. Madrid: Editorial Académica Española.

Barrios Rozúa, José Manuel. 2010. "José de Contreras. Un pionero de la arquitectura neoárabe. Sus trabajos en la Alhambra." In La invención del estilo hispano-magrebí. Presente y futuro del pasado, edited by José Antonio González Alcantud, 311-338. Barcelona: Anthropos.

Berríos, Pablo, Eva Cancino, Claudio Guerrero, Isidora Parra, Kaliuska Santibáñez, y Natalia Vargas. 2009. "Las bellas artes en la Atenas de Sudamérica: cultura y esfera publica en la República Conservadora." In Del taller a las aulas. La institución moderna del arte en Chile (1797-1910), 127-182. Santiago: Estudios de Arte. Santiago.

Blanco, Arturo. 1924. Vida y obras del arquitecto don Fermín Vivaceta precursor de la sociabilidad obrera en Chile. Santiago: Talleres Gráficos.

Boone, Elizabeth. 2011. "Marginalizing Spain at the Chicago Columbian Exposition of 1893." Centering the Margins of Nineteenth-Century Art. Nineteenth Century Studies 25: 199-220.

Brunet de Baines, Claude Francois. 1853. Curso de arquitectura: escrito en francés para el Instituto Nacional de Chile. Santiago: Imprenta Julio Belin \& Cia.

Bueno Fidel, María José. 1987. Arquitectura y nacionalismo. Pabellones españoles en las EXposiciones Universales del siglo XIX. Málaga: Universidad de Málaga.

Calatrava, Juan. 2014. "Paradigma islámico e historia de la arquitectura española: de la Exposición Universales al Manifiesto de la Alhambra." In Las exposiciones de arquitectura y la arquitectura de las exposiciones: Las arquitectura española y las exposiciones internacionales (1929-1975), edited by José Manuel Pozo Municio, Héctor García-Diego Villarías, and Beatriz Caballero, 27-36. Pamplona: Universidad de Navarra. 
Calatrava, Juan. 2015. “El arte hispanomusulmán y las exposiciones universales de Owen Jones a Leopoldo Torres Balbás." Awraq 11: 7-31.

Calvo Capilla, Susana. 2008. "La ampliación califal de la mezquita de Córdoba: mensajes, formas y funciones." Goya 323: 89-106.

Calvo Capilla, Susana. 2010. "Justicia, misericordia y cristianismo: relectura de las inscripciones coránicas de la mezquita de Córdoba en el siglo X." Al-Qantara 31 (1): 149-187. https:// doi.org/10.3989/alqantara.2010.v31.i1.111

Canogar, Daniel. 2000. Pabellones españoles en las Exposiciones Universales. Madrid: Sociedad Estatal Hannover.

Casado Alcalde, Esteban. 2004. "Arquitectos de la Academia de España en Roma (siglo XIX)." Archivo Español de Arte 77 (306): 129-138.

Çelik, Zeynep. 1992. Displaying the Orient: Architecture of Islam at Nineteenth-Century World's Fairs. Berkeley: University of California Press. https://doi.org/10.1017/s0020743800059808

Danby, Miles, and Weinreb, Matthew. 1997. The fires of excellence: Spanish and Portuguese oriental architecture. Garnet: Reading.

Davis, George. 1893. The World's Columbian Exposition, Chicago, 1893. Chicago: Philadelphia International Pub. Co. https://doi. org/10.5962/bhl.title.65258

Domínguez, Tomás. 2001. “Mausoleos exóticos. Eclecticismo y reinvención estilística de Teobaldo Brugnoli." ARQ 48: 50-53.

Dümmer Scheel, Sylvia. 2012. Sin tropicalismos ni exageraciones. La construcción de la imagen de Chile para la Exposición Iberoamericana de Sevilla en 1929. Santiago: RIL Editores. https:// doi.org/10.4067/s0717-71942014000100013

Eggleton, Lara. 2012. "History in the making: the ornament of the Alhambra and the pastfacing present." Journal of Art Historiography 6. Accessed: November 11, 2017. https://arthistoriography.wordpress.com/number-6-june-2012-2/

Farrés Delgado, Yasser. 2015. "Colonialidad territorial y evolución urbana en La Habana." Apuntes 28-1: 8-23.
Ferrán Oliva, Joan. 2009. La saga de los catalanes en Cuba. Barcelona: Ediciones Casa Amèrica Catalunya.

Flinn, John Joseph. 1893. Official guide to the World's Columbian exposition. Chicago: Press Chicago, vol. III.

Galeno-Ibaceta, Claudio. 2011. "Chile y sus hospitales en pabellones en la Exposición Universal de París de 1889." In Sistema arquitectónico de pabellones en hospitales de América Latina, edited by María Lilia González Servín, 87-94. Coyoacán: Universidad Nacional Autónoma de México.

Gámiz Gordo, Antonio. 2010. “Las vistas de España del viajero David Roberts, pintor de paisajes y arquitecturas hacia 1833." Expresión Gráfica Arquitectónica 15: 54-65.

Giese, Francine and Ariane Varela Braga, eds. 2017. Die Appropriation des Orients, SGMOIK Bulletin, 44.

Giese, Francine, and Ariane Varela Braga, eds. 2016. The Power of Symbols. The Alhambra in a Global Context. Berne: Peter Lang.

Giese, Francine, Ariane Varela Braga, Helena Lahoz Kopiske, Katrin Kaufmann, Laura Castro Royo, and Sarah Keller. 2016. "Resplendence of al-Andalus. Exchange and Transfer Processes in Mudéjar and neo-Moorish Architecture." Asiatische Studien 70, 4: 1307-1353. https://doi.org/10.1515/asia-2016-0499

Gutiérrez Viñuales, Rodrigo. 2006. “El orientalismo en el imaginario artístico y urbano de Iberoamérica. Exotismo, fascinación e identidad." In El orientalismo desde el sur, edited by José Antonio González Alcantud, 231-259. Sevilla: Anthropos.

Gutiérrez Viñuales, Rodrigo. 2006. "La seducción de la Alhambra. Recreaciones islámicas en América." In Mudéjar Hispano y Americano. Itinerarios culturales mexicanos, edited by Rafael López Guzmán, 166-173. Granada: El Legado Andalusí.

Gutiérrez Viñuales, Rodrigo. 2008. "La Alhambra viajera. Rutas americanas de una obsesión romántica." In La Alhambra: lugar de la memoria y el diálogo, edited by José Antonio 
González Alcantud and Akmir Abdellouahed, 95-122. Granada: Comares Editorial.

Gutiérrez Viñuales, Rodrigo. 2009. "Horizontes historicistas en Iberoamérica. El Neoprehispánico y el Neoárabe, exotismo e identidad." In Arquitectura escrita. Doscientos años de arquitectura mexicana, edited by Johanna Lozoya and Tomás Pérez, 87-99. México: Instituto Nacional de Antropología e Historia.

Gutiérrez Viñuales, Rodrigo. 2016. "Arquitectura morisca en Sudamérica." In Alhambras. Arquitectura neoárabe en Latinoamérica, edited by Rafael López Guzmán and Rodrigo Gutiérrez Viñuales, 195-213. Granada: Editorial Almed.

Handy, Moses. 1893. The Official Directory of the World's Columbian Exposition. Chicago: Conkey Company.

Hernández Cornejo, Roberto. 1930. El salitre (resumen histórico desde su descubrimiento y explotación). Valparaíso: Fisher Hermanos.

Hernando Carrasco, Javier. 1989. Arquitectura en España, 1770-1900. Madrid: Cátedra.

Hurtado, Marcelo, Manuel Salazar, and Gonzalo Muñoz. 2016. "Construction features of the historical architecture in the sea port city of Valparaíso: architect E. O. F. Harrington's brick masonry buildings." Revista de la Construcción 15 (3): 67-76.

Ives, Halsey. 1893-1894. The Dream City: A Portfolio of Photographic Views of the World's Columbian Exposition. St. Louis: Thompson.

Jiménez Martín, Alfonso. 2015. “Notas sobre los dibujos de las Antigüedades árabes." In Antigüedades árabes de España, edited by Antonio Almagro Gorbea, 31-43. Madrid: Real Academia de Bellas Artes de San Fernando.

Lillo Brevis, Andrés. 2017. "Influencias orientalistas en la fachada del Palacio Barazarte de Viña del Mar: Una mirada al eclecticismo arquitectónico chileno de finales del siglo XIX e inicios del siglo XX." Trabajo del Magíster en Historia. Seminario de Especialización II. Viña del Mar: Pontificia Universidad Católica de Valparaíso.

López Guzmán, Rafael, and Aurora Yaratzeth Avilés García. 2015. "Presencia mexicana en la Exposición Universal. El Pabellón morisco de Nueva Orleans (1884)." Awraq 11: 59-84.

López Guzmán, Rafael, y Rodrigo Gutiérrez Viñuales, eds. 2016. Alhambras: Arquitectura neoárabe en Latinoamérica. Granada: Almed Ediciones.

López Guzmán, Rafael. 2015. “Influencias hispanas en la arquitectura de La Habana entre los siglos XIX y XX." Laboratorio de Arte 27: 385-400.

López Quintáns, Javier. 2012. “Disertaciones y descubrimientos en Viaje en España de Rafael Sanhueza Lizardi." Philologia Hispalensis 26, 3-4: 83-95.

Martin-Márquez, Susan. 2008. Disorientations: Spanish Colonialism in Africa and the Performance of Identity. New Haven: Yale University Press.

Martuccelli Casanova, Elio. 2006. “Lima, capital de la Patria Nueva: el doble Centenario de la Independencia en el Perú." Apuntes 19 (2): 256-273.

McSweeney, Anna. 2015. "Versions and Visions of the Alhambra in the Nineteenth-Century Ottoman World." West 86th: A Journal of Decorative Arts, Design History, and Material Culture 22 (1): 44-69.

Milos Montes, Mariana. 2014. "La construcción de la identidad chilena a partir de la Exposición Universal de París de 1889." Ph diss., Universidad de Chile.

Momplet Mínguez, Antonio. 2012. “De la fusión a la difusión en el arte de la Córdoba califal: la ampliación de al-Hakam II en la mezquita aljama." Anales de Historia del Arte. Número Especial II 237 (22): 237-258.

Moráis Morán, José Alberto. 2017. “Los islamismos de la arquitectura chilena decimonónica y otras referencias orientales." ARQ Santiago 95: 62-73. https://doi.org/10.4067/s071769962017000100062

Morales, Ambrosio de. 1792. Crónica General de España. Madrid: Benito Cano, vol. 10.

Murillo Sandoval, Juan David. 2015. “De lo natural y lo nacional. Representaciones de la naturaleza explotable en la Exposición Interna- 
cional de Chile de 1875." Historia (Santiago) 1, 48. Accessed December 12, 2016. https:// doi.org/10.4067/s0717-71942015000100007

Navascués Palacio, Pedro. 1973. Arquitectura y arquitectos madrileños del siglo XIX. Madrid: Instituto de Estudios Madrileños.

Navascués Palacio, Pedro. 2001. "Recorrido artístico por la España romántica." Descubrir el Arte 30: 41-49.

Ortiz Pradas, Daniel. 2010. "En busca de una arquitectura nacional. Mélida y San Juan de los Reyes de Toledo." Anales de Historia del Arte. Volumen Extraordinario: 257-271.

Pallarés Torres, Mirtha. 2015. "La arquitectura religiosa en Santiago de Chile 1850-1950. Razones de las reminiscencias góticas." PhD diss., Universidad Politécnica de Madrid.

Panadero Peropadre, Nieves. 1994. "Recuerdos de la Alhambra: Rafael Contreras y el Gabinete árabe del Palacio Real de Aranjuez." Reales Sitios 122: 33-40.

Peña Muñoz, Manuel. 2001. Memorial de la tierra larga: crónicas chilenas. Santiago: Ril Editores.

Plá, José. 1941. Costa Brava. Guía General y Verídica. Barcelona: Destino.

Puig y Valls, Rafael. 1894. Estados Unidos, Exposición Universal de Chicago, México, Cuba y Puerto. México: Luis Tasso.

Ramos Cerna, Horacio. 2014. "Destrucción y reinvención de la Plaza de Armas. Estilo neocolonial y modernización urbana en Lima, 1924-1954." PhD diss., Pontificia Universidad Católica de Perú.

Raquejo Grado, Tonia. 1988. “La Alhambra en el Museo Victoria \& Albert. Un catálogo de las piezas de la Alhambra y de algunas obras neonazaríes." Cuadernos de arte e iconografía 1: 201-244.

Raquejo Grado, Tonia. 1990. El palacio encantado: la Alhambra en el arte británico. Madrid: Taurus.

Raquejo Grado, Tonia. 1995. “El Alhambresco: Constitución de la imagen romántica de AlAndalus." In La imagen romántica del legado andalusí, 29-36. Barcelona-Madrid: Lunwerg Editores.

Río Barrio, Luis Fernando del, y José Fidel SobreviIla Carlino. 2008. "Asociaciones de españoles en Chile (1850-1950)." In El asociacionismo en la emigración española a América, edited by Juan Andrés Blanco Rodríguez, 503-523. Salamanca: Junta de Castilla y León.

Riquelme Sepúlveda, Fernando. 1990. "Fermín Vivaceta. El arquitecto y su obra." Revista de Arquitectura 1 (2-7): 2-7.

Rodríguez Cobos, Luis. 1983. Arquitectura limeña: paisajes de una utopía. Lima: Colegio de Arquitectos del Perú.

Rodríguez Domingo, José Manuel. 1997. "La Alhambra efímera: el pabellón de España en la Exposición Universal de Bruselas (1910)." Cuadernos de Arte de la Universidad de Granada 28: 125-139.

Rodríguez Domingo, José Manuel. 1997. “La arquitectura «neoárabe» en España: el medievalismo islámico en la cultura arquitectónica española (1840-1930)." PhD diss., Universidad de Granada.

Rodríguez Domingo, José Manuel. 1999. “Neomudéjar versus neomusulmán: definición y concepción del medievalismo islámico en España." Espacio, Tiempo y Forma. Serie VII. Historia del Arte 12: 265-285.

Roelle, Jenna Rose. 2009. "That romantic fortress: British depictions of the Alhambra, 1815-1837." PhD diss., University of Oregon: Department of Art History. Accessed: December 15, 2017. http://citeseerx.ist.psu.edu/ viewdoc.

Roig de Leuchsenring, Emilio. 1963. La Habana. Apuntes Históricos. La Habana: Consejo Nacional de Cultura, vol. II.

Rosser-Owen, Mariam. 2011. "Coleccionar la Alhambra: Owen Jones y la España Islámica en el South Kensington Museum." In Owen Jones y la Alhambra, edited by Juan Calatrava, 42-69. Granada: Patronato de la Alhambra y Generalife.

Rossiter, Johnson, ed. 1897. A History of the World's Columbian Exposition, Held in Chicago in 1893. New York: Appleton. 
Sainte Marie, Darío. 1945. Perú en cifras, 19441945. Lima: Empresa Gráfica Scheuch.

Sanhueza Lizardi, Rafael. 1889. Viaje en España. París: Garnier.

Saward, Jeff. 2008. "The Origin of Mirror \& Wooden Panel Mazes." Caerdroia 37: 4-12.

Sazatornil Ruiz, Luis. 2008. "Andalucismo y Arquitectura en las Exposiciones Universales. 1867-1900." In Andalucía: Una Imagen en Europa (1830-1929), edited by Luis Méndez Rodríguez, s. p. Sevilla: Fundación Centro de Estudios Andaluces. Consejería de la Presidencia. Junta de Andalucía.

Sazatornil Ruiz, Luis. 2012. "De Diebitsch a Hénard: el 'estilo Alhambra' y la industrialización del orientalismo." In Orientalismos. Arte y Arquitectura entre Granada y Venecia, edited by Juan Calatrava y Guido Zucconi, 53-72. Madrid: Abada.

Shepp, James, and Daniel Shepp. 1893. Shepp's World's Fair Photographed. Chicago: Globe Bible.

Soraluce Blond, José Ramón. 2001. "Arquitectura cubana: vernácula, colonial y ecléctica." In Arquitectura de la casa cubana, s. p. A Coruña: Universidade da Coruña. Accesed May 1, 2017. http://ruc.udc.es/dspace/handle/2183/7369.

Swinburne, Henry. 1787. Travels through Spain in the years 1775 and 1776. London: Davis.
Twiss, Richard. 1775. Travels through Portugal and Spain, in 1772 and 1773. London: G. Robinson.

Valenzuela, María Paz. 2014. "La enseñanza de la arquitectura en Chile." De arquitectura 28-29: 54-55. https://doi.org/10.5354/07195427.2014.37094

Valero Juan, Eva María. 2003. Lima en la tradición literaria del Perú. De la leyenda urbana a la disolución del mito, Ensayos/Scriptura 12. Lleida: Ediciones de la Universidad de Lleida.

Vázquez Cienfuegos, Sigfrido. 2009. "Omnia vanitas: festejos en honor de Godoy en La Habana en 1807." Ibero-americana pragensia supplementum 25: 115-138.

Vázquez, Adolfo, y Jorge Young. 1952. Historia del turf nacional, 1864-1945. Lima: Miranda.

Villegas Torres, Fernando. 2013. Vínculos artísticos entre España y Perú (1892-1929): elementos para la construcción del imaginario nacional peruano. PhD diss., Madrid: Universidad Complutense de Madrid.

Waisberg, Myriam. 1988. Casas de Playa Ancha: La vivienda a fines del siglo XIX en Valparaíso. Valparaíso: Fondo Nacional de Desarrollo Científico y Tecnológico.

White, Trumbull, and William Igleheart. 1893. The World's Columbian Exposition, Chicago, 1893. Philadelphia: Historical Publishing. 